\title{
Analysis of uterine gene expression in interleukin-15 knockout mice reveals uterine natural killer cells do not play a major role in decidualization and associated angiogenesis
}

\author{
Brent M Bany ${ }^{1,2}$, Charles A Scott ${ }^{1}$ and Kirsten S Eckstrum ${ }^{1}$ \\ Departments of ${ }^{1}$ Physiology and ${ }^{2}$ Obstetrics and Gynecology, Southern Illinois University School of Medicine, \\ Carbondale, Illinois 62901, USA
}

Correspondence should be addressed to B M Bany at Department of Physiology, Southern Illinois University School of Medicine; Email: bbany@siumed.edu

\begin{abstract}
During decidualization, uterine natural killer (uNK) cells are the most abundant immune cell types found in the uterus. Although it is well known that they play key roles in spiral arteriole modification and the maintenance of decidual integrity seen after mid-pregnancy, their roles in the differentiation of decidual cells and accompanying angiogenesis during the process of decidualization is less well characterized. To address this, we used whole-genome Illumina BeadChip analysis to compare the gene expression profiles in implantation segments of the uterus during decidualization on day 7.5 of pregnancy between wild-type and uNK cell-deficient (interleukin-15-knockout) mice. We found almost 300 differentially expressed genes and verified the differential expression of $\sim 60$ using quantitative RT-PCR. Notably, there was a lack of differential expression of genes involved in decidualization and angiogenesis and this was also verified by quantitative RT-PCR. Similar endothelial cell densities and proliferation indices were also found in the endometrium between the implantation site tissues of wild-type and knockout mice undergoing decidualization. Overall, the results of this study reveal that uNK cells likely do not play a major role in decidualization and accompanying angiogenesis during implantation. In addition, the study identifies a large number of genes whose expression in implantation-site uterine tissue during decidualization depends on interleukin-15 expression in mice.

Reproduction (2012) 143 359-375
\end{abstract}

\section{Introduction}

Decidualization, the differentiation of the endometrium into the decidua, is a key process during implantation of the conceptus in rodents and humans and has been covered by a number of reviews (Abrahamsohn \& Zorn 1993, Dunn et al. 2003, Gellersen et al. 2007, Herington et al. 2009, Ramathal et al. 2010). Briefly, in mice, the decidual tissue provides the nutritive environment for $\sim 5$ days in which the embryo and placenta develop. After mid-pregnancy, the functional placenta is formed and takes over providing the nutrients to the fetus. Several changes occur in the uterus during decidualization, but the hallmark is the rapid proliferation and then transdifferentiation of fibroblast-like endometrial stromal cells into the epithelial-like decidual cells, usually called decidual cell differentiation. In the mouse, this is dependent on the actions of several hormones including progesterone and bone morphogenic protein 2 (BMP2; Lee et al. 2007) and is accompanied by an increase in the expression of decidual markers such as liver/bone/ kidney alkaline phosphatase (Akp1; Herington et al. 2009) and prolactin family 8 , subfamily a, member 2
(Prl8a2; Bany \& Cross 2006), and a massive increase in uterine weight. To support this tissue growth, another important process during decidualization of the endometrium is angiogenesis or neo-angiogenesis (Torry et al. 2007, Laws et al. 2008, Demir et al. 2010). Critical to this is the endometrial expression of several genes such as vascular endothelial growth factor A (Vegfa; Chakraborty et al. 1995, Halder et al. 2000), prostaglandin endoperoxide synthase 2 (Ptgs2) plus angiopoietin 2 (Angpt2) (Matsumoto et al. 2002), and gap junction protein alpha 1 (Gja1; Laws et al. 2008).

The most abundant immune cell types in the uterus during decidualization are uterine natural killer (uNK) cells. Current dogma for mice is that there are two sources of uNK cells in the uterus during implantation (Zhang et al. 2009, 2011). One population of uNK cells are dolichos biflorus agglutinin (DBA) lectin-positive $\left(\mathrm{DBA}^{+}\right)$and have granules that stain positive using periodic acid Schiff staining $\left(\mathrm{PAS}^{+}\right)$. The DBA ${ }^{+} \mathrm{PAS}^{+}$ uNK cells are believed to be derived from circulating lymphocyte progenitor cells, which upon entering the uterus as immature non-granulated uNK cells, begin 
expressing DBA lectin and undergo maturation into large granulated NK cells. The other source of UNK cells in the uterus comes from the resident $\mathrm{UNK}$ cells which are DBA lectin-negative $\left(\mathrm{DBA}^{-}\right)$but are $\mathrm{PAS}^{+}$. A great deal of work has been conducted on the functions of uNK cells in mice and has involved the use of several genetic models, including interleukin-15 knockout $\left(I / 15^{-/-}\right)$ mice, where uNK cells are absent from the uterus during decidualization (Croy et al. 2003b). All of these studies conclusively showed that uNK cells play a key role in maintaining decidual integrity and the characteristic modification of the spiral arteries which is clearly seen only after mid-pregnancy. However, it should be noted that the uNK cell deficient $I / 15^{-1-}$ mice are fertile, have normal gestation times and comparable litter sizes to wild-type mice (Barber \& Pollard 2003). However, although little is really known about the role of uNK cells in decidualization and accompanying angiogenesis, it has been speculated that they play a role in decidualization. For example, it has been speculated that UNK cells play a role in uterine angiogenesis because in humans and mice, they express VEGFC and Vegfa respectively (Wang et al. 2000, Lash et al. 2006). However, a clear role for uNK cells in decidual cell differentiation and angiogenesis during decidualization is currently not established.

The present study was conducted to more closely examine the potential aberrant expression of genes involved in decidual cell differentiation and angiogenesis in the mouse uterus during decidualization in $1 / 15^{-1-}$ mice. The results support the hypothesis that uNK cells in mice do not play a major role in decidual cell differentiation as well as angiogenesis during decidualization. However, the microarray analysis reveals the identity of almost 300 genes whose expression is altered in the implantation areas of the uterus of $/ 115^{-/-}$ mice, some of which were investigated further.

\section{Results}

\section{Microarray analysis}

To determine the potential effect of uNK cell depletion on uterine gene expression during decidualization, we compared the global mRNA levels between RNA samples in day 7.5 implantation segment (IS) tissues from $/ / 15$ wild-type $\left(/ / 15^{+/+}\right)$and knockout mice $\left(I / 15^{-/-}\right)$using Illumina BeadChip microarray analysis. day 7.5 of pregnancy was chosen because by this day decidual growth is well underway and uNK cells are very abundant in IS tissue of the uterus (Herington \& Bany $2007 b$ ). Of the 46633 probes, signals for 14148 were detected significantly above background in all samples. Analysis of these data suggested that 285 of these probes showed a significant difference in the level of hybridization signals between samples from $1 / 15^{-/-}$and $1 / 15^{+/+}$mice and could be assigned a gene symbol.
These probes represented the mRNAs for 267 different genes that were differentially expressed, with 150 and 117 having greater hybridization signals in IS tissue from $1 / 15^{+/+}$and $1 / 15^{-1-}$ mice respectively. Genes listed in Tables 1 and 2 are those differentially expressed twofold or greater in the IS tissue of $I / 15^{+/+}$and $/ / 15^{-/-}$mice respectively. Further analysis of the microarray data revealed that hybridization signals for 29 and 7 probes, respectively, were found in IS tissues of only $1115^{+/+}$ (Table 3) or $1115^{-1-}$ (Table 4) mice. These represented probes representing 26 and 7 genes respectively. Full annotation of all 321 probes representing differential expression of 300 genes is shown in Supplementary Table 1, see section on supplementary data given at the end of this article. Finally, the hypogeometric tests for gene ontology (GO) terms of the list of all differentially expressed genes revealed significant over- and underrepresentation of GO terms for molecular function (Supplementary Table 2, see section on supplementary data given at the end of this article). The top overrepresented biological process was proteolysis and several immune cell-related processes were in the list.

\section{Expression of genes involved in decidualization}

Although it is clear that 'decidual integrity' depends on the presence of uNK cells (Ashkar et al. 2003, Monk et al. 2005), it has not been solidly established whether or not these cells play a role in decidual cell differentiation. The expression of many genes in rodent endometrial stromal cells is known to increase during decidual cell differentiation. Notably, in this study, the mRNA levels of two of the more commonly used decidual markers, Prl8a2 and Akpl, were not different between the IS tissue of $/ 115^{+/+}$compared with $1 / 15^{-/-}$ mice. Two major regulators of decidualization are BMP2 and progesterone (Lee et al. 2007). The mRNA levels of $B m p 2$ and progesterone receptor (Pgr) were not found to be differentially expressed in the microarray analysis. As shown in Fig. 1A, we verified the lack of differential mRNA levels for Bmp2 as well as several BMP2 target genes in the uterus such as FK506 binding protein 3 (Fkbp3), 4 (Fkbp4), and 5 (Fkbp5). In addition, mechanistic targets of rapamycin (Mtor/Frap1), follistatin $(F s t)$, and inhibitor of DNA binding 1 (Id1) (Lee et al. 2007) were not significantly $(P>0.05)$ different in IS tissue between $I / 15^{+/+}$and $/ 115^{-1-}$ mice (Fig. $1 \mathrm{~A}$ ). In a similar fashion, we verified that Pgr mRNA levels did not differ in IS tissues between these mice (Fig. 1A). Finally, Kruppel-like factor 5 (Klf5) is expressed in the uterus (Watanabe et al. 1999) and is known to be involved in vascular remodeling and angiogenesis (Nagai et al. 2005). Klf5 mRNA levels in the IS tissues of the uterus significantly $(P<0.05)$ increased compared with nonimplantation segment (NIS) tissues on days 5.5-8.5 of pregnancy in $/ 115^{+/+}$mice (Fig. 1B). Although the microarray analysis indicated differential expression of 
Table 1 Genes whose steady-state mRNA levels are significantly greater in IS tissue from day 7.5 pregnant $/ 15^{+/+}$mice compared with that of $1 / 15^{-/-}$mice by at least an average of twofold. Probe ID indicates Illumina Probe identification number and fold refers to average fold difference mRNA levels in IS tissue of $I / 15^{+/+}$relative to $/ 115^{-/-}$mice.

\begin{tabular}{|c|c|c|c|}
\hline Gene symbol & Name & Fold & Probe ID \\
\hline Spp1 & Secreted phosphoprotein 1 & 11.931 & 2470609 \\
\hline Gdpd3 & Glycerophosphodiester phosphodiesterase domain containing 3 & 6.423 & 6110292 \\
\hline Ear11 & Eosinophil-associated, ribonuclease A family, member 11 & 5.938 & 2260292 \\
\hline Tcrb-J & T-cell receptor beta, joining region & 5.040 & 103800086 \\
\hline Rgs5 & Regulator of G-protein signaling 5 & 3.982 & 101410068 \\
\hline Aldh1a3 & Aldehyde dehydrogenase family 1 , subfamily A3 & 3.775 & 105700162 \\
\hline Pdgfrl & Platelet-derived growth factor receptor-like & 3.749 & 870168 \\
\hline Tnfrsf9 & Tumor necrosis factor receptor superfamily, member 9 & 3.138 & 2510400 \\
\hline Csrnp1 & Cysteine-serine-rich nuclear protein 1 & 3.095 & 1230053 \\
\hline Tpsab1 & Tryptase alpha/beta 1 & 3.095 & 1400347 \\
\hline Pdpn & Podoplanin & 3.095 & 4640280 \\
\hline Pstpip1 & Proline-serine-threonine phosphatase-interacting protein 1 & 2.921 & 3190156 \\
\hline Degs2 & Degenerative spermatocyte homolog 2, lipid desaturase & 2.915 & 1170056 \\
\hline Rac2 & RAS-related $\mathrm{C} 3$ botulinum substrate 2 & 2.802 & 1580541 \\
\hline Irf8 & Interferon regulatory factor 8 & 2.751 & 610161 \\
\hline Necap2 & NECAP endocytosis associated 2 & 2.726 & 6200048 \\
\hline Cldn15 & Claudin 15 & 2.682 & 4150270 \\
\hline Selplg & Selectin, platelet (p-selectin) ligand & 2.651 & 1770167 \\
\hline Fbln 1 & Fibulin 1 & 2.585 & 2480059 \\
\hline Sprr2d & Small proline-rich protein 2D & 2.579 & 1340458 \\
\hline A430104N18Rik & RIKEN cDNA A430104N18 gene & 2.537 & 106510711 \\
\hline Cinp & Cyclin-dependent kinase 2 interacting protein & 2.514 & 106770484 \\
\hline Ncf4 & Neutrophil cytosolic factor 4 & 2.474 & 610164 \\
\hline Tbc1d 20 & TBC1 domain family, member 20 & 2.440 & 7000286 \\
\hline Cnot7 & CCR4-NOT transcription complex, subunit 7 & 2.428 & 101570114 \\
\hline Coro1a & Coronin, actin binding protein $1 \mathrm{~A}$ & 2.417 & 3140609 \\
\hline Gn/2 & Guanine nucleotide binding protein-like 2 & 2.406 & 6620022 \\
\hline Myo1g & Myosin IG & 2.395 & 2970358 \\
\hline $\mathrm{Fb} \ln 2$ & Fibulin 2 & 2.395 & 3440215 \\
\hline Coro1a & Coronin, actin binding protein $1 \mathrm{~A}$ & 2.367 & 3190020 \\
\hline Lat2 & Linker for activation of T cells family, member 2 & 2.362 & 5340440 \\
\hline Spink2 & Serine peptidase inhibitor, Kazal type 2 & 2.357 & 3990093 \\
\hline Wrn & Werner syndrome homolog & 2.329 & 540692 \\
\hline $\mathrm{Cd} 47$ & $\begin{array}{l}\text { CD47 antigen (Rh-related antigen, integrin-associated signal } \\
\text { transducer) }\end{array}$ & 2.303 & 103390731 \\
\hline 9130230L23Rik & RIKEN cDNA 9130230L23 gene & 2.271 & 2190452 \\
\hline Pnpla3 & Patatin-like phospholipase domain containing 3 & 2.266 & 5050551 \\
\hline Rab44 & RAB44, member RAS oncogene family & 2.240 & 102230139 \\
\hline Farsa & Phenylalanyl-tRNA synthetase, alpha subunit & 2.235 & 2650593 \\
\hline Ocel1 & Occludin/ELL domain containing 1 & 2.204 & 2470088 \\
\hline Anxa8 & Annexin A8 & 2.194 & 4780022 \\
\hline Akr1b8 & Aldo-keto reductase family 1 , member B8 & 2.184 & 3120288 \\
\hline Rap1gap & Rap1 GTPase-activating protein & 2.184 & 101850672 \\
\hline Retnla & Resistin-like alpha & 2.168 & 3840138 \\
\hline Pfpl & Pore forming protein-like & 2.149 & 6450670 \\
\hline Fam83g & Family with sequence similarity 83 , member $G$ & 2.144 & 103130735 \\
\hline Col5a2 & Collagen, type $\mathrm{V}$, alpha 2 & 2.139 & 104280100 \\
\hline Doxl2 & Diamine oxidase-like protein 2 & 2.134 & 104780056 \\
\hline Ccdc114 & Coiled-coil domain containing 114 & 2.129 & 104610181 \\
\hline Pcsk5 & Proprotein convertase subtilisin/kexin type 5 & 2.109 & 5720600 \\
\hline Emid2 & EMI domain containing 2 & 2.099 & 360400 \\
\hline Serhl & Serine hydrolase-like & 2.090 & 2470605 \\
\hline Ciapin1 & Cytokine-induced apoptosis inhibitor 1 & 2.080 & 2900114 \\
\hline Selplg & Selectin, platelet ( $p$-selectin) ligand & 2.056 & 101470563 \\
\hline$S f t 2 d 3$ & SFT2 domain containing 3 & 2.051 & 103060670 \\
\hline Oxsr1 & Oxidative-stress responsive 1 & 2.047 & 1500025 \\
\hline Alox5 & Arachidonate 5 -lipoxygenase & 2.037 & 105340280 \\
\hline Adamts7 & $\begin{array}{l}\text { A disintegrin-like and metallopeptidase (reprolysin type) with } \\
\text { thrombospondin type } 1 \text { motif, } 7\end{array}$ & 2.023 & 3360368 \\
\hline Gabbr1 & Gamma-aminobutyric acid (GABA) B receptor, 1 & 2.000 & 101780504 \\
\hline
\end{tabular}


Table 2 Genes whose steady-state mRNA levels are significantly less in IS tissue from day $7.5 / / 15^{-/-}$pregnant mice compared with that of $/ / 15^{+/+}$ mice by twofold or greater. Probe ID denotes Illumina Probe identification number and fold indicates average fold difference mRNA levels in IS tissue of $I / 15^{+/+}$relative to $I 115^{-1-}$ mice.

\begin{tabular}{|c|c|c|c|}
\hline Gene symbol & Name & Fold & Probe ID \\
\hline $\lg k c$ & Immunoglobulin (Ig) and T-cell receptor & 11.628 & 1230347 \\
\hline $\lg k \mathrm{c}$ & Immunoglobulin kappa constant & 10.526 & 6370309 \\
\hline $\operatorname{lgh}-$ VJ558 & Immunoglobulin heavy chain (J558 family) & 9.709 & 60025 \\
\hline Ndufb10 & NADH dehydrogenase (ubiquinone) 1 beta subcomplex, 10 & 8.850 & 5900576 \\
\hline $\operatorname{lgh}-$ VJ558 & Immunoglobulin heavy chain (J558 family) & 8.333 & 1690184 \\
\hline Man2b1 & Mannosidase 2, alpha B1 & 6.410 & 106520575 \\
\hline Rassf8 & Ras association (RalGDS/AF-6) domain family (N-terminal) member 8 & 4.505 & 105690053 \\
\hline Glrx & Glutaredoxin & 4.444 & 3520471 \\
\hline SCOC & Short coiled-coil protein & 3.937 & 2230053 \\
\hline $\operatorname{Prd} 22$ & Peroxiredoxin 2 & 3.891 & 4010619 \\
\hline Arl3 & ADP-ribosylation factor-like 3 & 3.817 & 5690725 \\
\hline Trmt1 & TRM1 tRNA methyltransferase 1 homolog & 3.759 & 103780280 \\
\hline Pla2g12a & Phospholipase A2, group XIIA & 3.636 & 103390286 \\
\hline Sdhaf1 & Succinate dehydrogenase complex assembly factor 1 & 3.247 & 102230433 \\
\hline Rusc2 & RUN and $\mathrm{SH} 3$ domain containing 2 & 3.125 & 460168 \\
\hline Syne2 & Synaptic nuclear envelope 2 & 2.924 & 102260348 \\
\hline Col1a2 & Collagen, type I, alpha 2 & 2.801 & 380364 \\
\hline $\operatorname{Prcp}$ & Prolylcarboxypeptidase (angiotensinase C) & 2.801 & 7050746 \\
\hline Gpx2 & Glutathione peroxidase 2 & 2.717 & 6940619 \\
\hline Gm3322 & Predicted gene 3322 & 2.710 & 6660128 \\
\hline Timm9 & Translocase of inner mitochondrial membrane 9 & 2.611 & 1450019 \\
\hline S100a9 & S100 calcium binding protein A9 (calgranulin B) & 2.611 & 7050528 \\
\hline ВС003331 & cDNA sequence BC003331 & 2.525 & 1980164 \\
\hline Mtap7d2 & MAP7 domain containing 2 & 2.469 & 106860494 \\
\hline Rg9mtd1 & RNA (guanine-9-) methyltransferase domain containing 1 & 2.457 & 4480368 \\
\hline Gch1 & GTP cyclohydrolase 1 & 2.445 & 670364 \\
\hline Mmp3 & Matrix metallopeptidase 3 & 2.398 & 2650368 \\
\hline Trem2 & Triggering receptor expressed on myeloid cells 2 & 2.398 & 6290358 \\
\hline $\operatorname{Trf}$ & Transferrin & 2.381 & 1050193 \\
\hline Adamts9 & $\begin{array}{l}\text { A disintegrin-like and metallopeptidase (reprolysin type) with } \\
\text { thrombospondin type } 1 \text { motif, } 9\end{array}$ & 2.283 & 101580446 \\
\hline Mmp3 & Matrix metallopeptidase 3 & 2.232 & 2970056 \\
\hline H-T23 & Histocompatibility 2, T region locus 23 & 2.212 & 2850609 \\
\hline Sorcs2 & Sortilin-related VPS10 domain containing receptor 2 & 2.208 & 100460068 \\
\hline Wdr92 & WD repeat domain 92 & 2.203 & 5570097 \\
\hline Fut10 & Fucosyltransferase 10 & 2.174 & 103120039 \\
\hline Trim16 & Tripartite motif-containing 16 & 2.151 & 6510068 \\
\hline Hps1 & Hermansky-Pudlak syndrome 1 homolog (human) & 2.114 & 2510026 \\
\hline Nipal1 & NIPA-like domain containing 1 & 2.079 & 6130315 \\
\hline Aktip & Thymoma viral proto-oncogene 1 interacting protein & 2.066 & 6350575 \\
\hline Txnl4a & Thioredoxin-like 4A & 2.062 & 4120286 \\
\hline Gch1 & GTP cyclohydrolase 1 & 2.058 & 6550358 \\
\hline Nupr1 & Nuclear protein 1 & 2.053 & 1990524 \\
\hline Gstt2 & Glutathione $S$-transferase, theta 2 & 2.053 & 106650102 \\
\hline Rad23a & RAD23a homolog & 2.045 & 670082 \\
\hline Vps35 & Vacuolar protein sorting 35 & 2.045 & 7050687 \\
\hline$C d k n 2 b$ & Cyclin-dependent kinase inhibitor 2B ( 15 , inhibits CDK4) & 2.033 & 6020040 \\
\hline Hist1h4f & Histone cluster $1, \mathrm{H} 4 \mathrm{f}$ & 2.033 & 102450672 \\
\hline$D b t$ & Dihydrolipoamide branched chain transacylase E2 & 2.028 & 106180717 \\
\hline
\end{tabular}

KIf5 in IS tissues of $/ 115^{+/+}$compared with $/ 115^{-/-}$mice on day 7.5 (Table 3), we did not detect a significant $(P>0.05)$ difference between these tissues using quantitative RT-PCR (qRT-PCR; Fig. 1C).

\section{Expression of genes involved in angiogenesis}

Previous work suggests that uNK cells express genes involved in angiogenesis and thus may play a role in endometrial angiogenesis during implantation (Lash et al. 2006, Li et al. 2008, Kalkunte et al. 2009). Indeed, current dogma suggests that activated uNK cells are critical for endometrial angiogenesis that occurs in early implantation site development (Santoni et al. 2008, Petitbarat et al. 2010). Therefore, we expected abnormalities in uterine angiogenesis during decidualization in the IS tissue of the $1 / 15^{-1-}$ mice due to the lack of uNK cells. Expression of disintegrin-like and metallopeptidase 9 (Adamts9) increases in the mouse uterus during implantation and is localized mainly to a subpopulation of vascular endothelial cells in the endometrium (Jungers et al. 2005). Since ADAMTS9 is an anti-angiogenic factor 
Table 3 Genes whose steady-state mRNA levels were only significantly above background in IS tissue from day $7.5 / / 15^{+/+}$mice. Probe ID indicates Illumina Probe identification number.

\begin{tabular}{|c|c|c|}
\hline Gene symbol & Name & Probe ID \\
\hline 2010011120Rik & RIKEN cDNA 2010011120 gene & 102900270 \\
\hline 6330403K07Rik & RIKEN cDNA 6330403K07 gene & 2060504 \\
\hline Abca5 & ATP-binding cassette, subfamily A (ABC1), member 5 & 1660110 \\
\hline Avil & Advillin & 5690452 \\
\hline Ctsg & Cathepsin G & 1190711 \\
\hline Ctsw & Cathepsin W & 360368 \\
\hline Fcho1 & FCH domain only 1 & 1240411 \\
\hline Fgfr1op2 & FGFR1 oncogene partner 2 & 60538 \\
\hline Fggy & FGGY carbohydrate kinase domain containing & 7100026 \\
\hline Gm949 & Predicted gene 949 & 104480131 \\
\hline Gzmd & Granzyme D & 4920368 \\
\hline Gzme & Granzyme E & 1990112 \\
\hline Gzme & Granzyme E & 5080292 \\
\hline Gzmf & Granzyme F & 6200008 \\
\hline Gzmg & Granzyme G & 1230341 \\
\hline Klf5 & Kruppel-like factor 5 & 104150152 \\
\hline Klrd1 & Killer cell lectin-like receptor, subfamily D, member 1 & 3190114 \\
\hline Klrg1 & Killer cell lectin-like receptor subfamily G, member 1 & 2360133 \\
\hline Ltb4r1 & Leukotriene B4 receptor 1 & 1770056 \\
\hline Nkg7 & Natural killer cell group 7 sequence & 1780390 \\
\hline Nkg7 & Natural killer cell group 7 sequence & 6370059 \\
\hline $\mathrm{Nmu}$ & Neuromedin U & 6400025 \\
\hline Prf1 & Perforin 1 (pore forming protein) & 6660309 \\
\hline Rasgef1c & RasGEF domain family, member 1C & 105420563 \\
\hline Sh2d2a & $\mathrm{SH} 2$ domain protein $2 \mathrm{~A}$ & 2970594 \\
\hline Tcrb-V8.2 & T-cell receptor beta, variable 13-2 & 3610048 \\
\hline Ttc27 & Tetratricopeptide repeat domain 27 & 1090280 \\
\hline$X_{C} / 1$ & Chemokine (C motif) ligand 1 & 3800504 \\
\hline Zbtb32 & Zinc finger and BTB domain containing 32 & 5900397 \\
\hline
\end{tabular}

(Koo et al. 2010), we verified that Adamts9 mRNA levels were significantly $(P<0.01)$ greater in the IS tissues from $I / 15^{-/-}$compared with those of $I / 15^{+/+}$mice (Fig. 2A). On the other hand, given that uNK cells are believed to play a role in angiogenesis, it was surprising that the microarray analysis did not reveal differential expression of any other genes that may be involved in angiogenesis or that are expressed in endothelial cells. Therefore, we assessed the expression of several of these genes using qRT-PCR. Vegfa, Vegfb, Vegfc, vascular endothelial growth factor D/FOS-induced growth factor (Figf), as well as prostaglandin-endoperoxide synthase 2 (Ptgs2) and inhibin betaB (Inhbb) mRNA levels were not significantly $(P>0.05)$ different in the IS tissues from $1 / 15^{+/+}$compared with $1 / 15^{-1-}$ mice on day 7.5 of pregnancy (Fig. 2A). To examine this in more detail, we measured mRNA levels of several other angiogenesisrelated genes as well as endothelial cell markers in the IS tissue of $/ / 15^{+/+}$and $/ / 15^{-/-}$mice on days 6.5-10.5 of pregnancy. Gja1, Angpt1, Angpt2, and runt-related transcription factor 1 (Runx1) may play a role in uterine angiogenesis during implantation (Bany \& Cross 2006, Hess et al. 2006, Ma \& Zhu 2007, Laws et al. 2008, Dong \& Chen 2009, Sur 2009). We verified that the expression of all four of these genes was not significantly $(P>0.05)$ different between the IS tissues from $1 / 15^{+/+}$ and $1 / 15^{-/-}$mice on each day of pregnancy examined (Fig. 2B-E). Endothelial cells strongly express CD34 antigen (Cd34), platelet/endothelial cell adhesion molecule 1 (Pecam1), endothelial-specific receptor tyrosine kinase (Tek), FMS-like tyrosine kinase 1 (Flt1), kinase insert domain protein receptor $(K d r)$, and Flt4 in the endometrium during decidualization (Wong et al. 1997, He et al. 1999, Halder et al. 2000, Matsumoto et al. 2002, Douglas et al. 2009). We verified no significant $(P>0.05)$ effect of genotype on the expression of all six of these genes between the IS tissues from $1 / 15^{+/+}$and $/ 115^{-/-}$mice on each day of pregnancy examined except on day 9.5 for Pecam 1 and Flt4 (Fig. 2F-K).

Table 4 Genes whose steady-state mRNA levels were only significantly above background in IS tissue from day $7.5 / 115^{-/-}$mice. Probe ID indicates Illumina Probe identification number.

\begin{tabular}{|c|c|c|}
\hline Gene symbol & Name & Probe ID \\
\hline $6720422 \mathrm{M} 22 \mathrm{Rik}$ & RIKEN cDNA 6720422M22 gene & 104590600 \\
\hline Gfpt2 & $\begin{array}{l}\text { Glutamine fructose-6-phosphate } \\
\text { transaminase } 2\end{array}$ & 102810242 \\
\hline Ighg2C & $\begin{array}{l}\text { Immunoglobulin heavy constant } \\
\text { gamma 2C }\end{array}$ & 360113 \\
\hline $\operatorname{Prd} 22$ & Peroxiredoxin 2 & 5340577 \\
\hline Slpi & $\begin{array}{l}\text { Secretory leukocyte peptidase } \\
\text { inhibitor }\end{array}$ & 2120446 \\
\hline Sspn & Sarcospan & 4670091 \\
\hline Wdr46 & WD repeat domain 46 & 6020601 \\
\hline
\end{tabular}



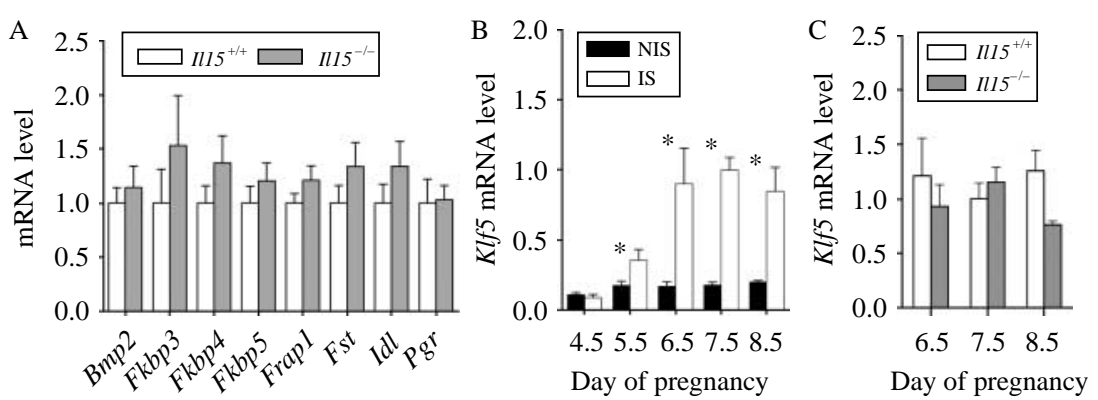

Figure 1 qRT-PCR assessment of the expression of genes involved in decidualization. (A) Bmp2 mRNA and the mRNAs of BMP2 downstream target genes plus progesterone receptor (Pgr) mRNA levels in IS tissue from day 7.5 pregnant $/ 115^{+/+}$and $/ 115^{-/-}$mice. Relative KIf5 mRNA levels in non-implantation (NIS) and implantation (IS) segments of the uterus (B) or IS segments from $/ / 15^{+/+}$and $/ / 15^{-/-}$mice (C) on days $5.5-8.5$ and days $6.5-8.5$ of pregnancy respectively. Bars represent the mean \pm S.E.M. $(n=4)$ and statistically significant difference in mRNA levels is denoted by asterisks $(* P<0.05)$.
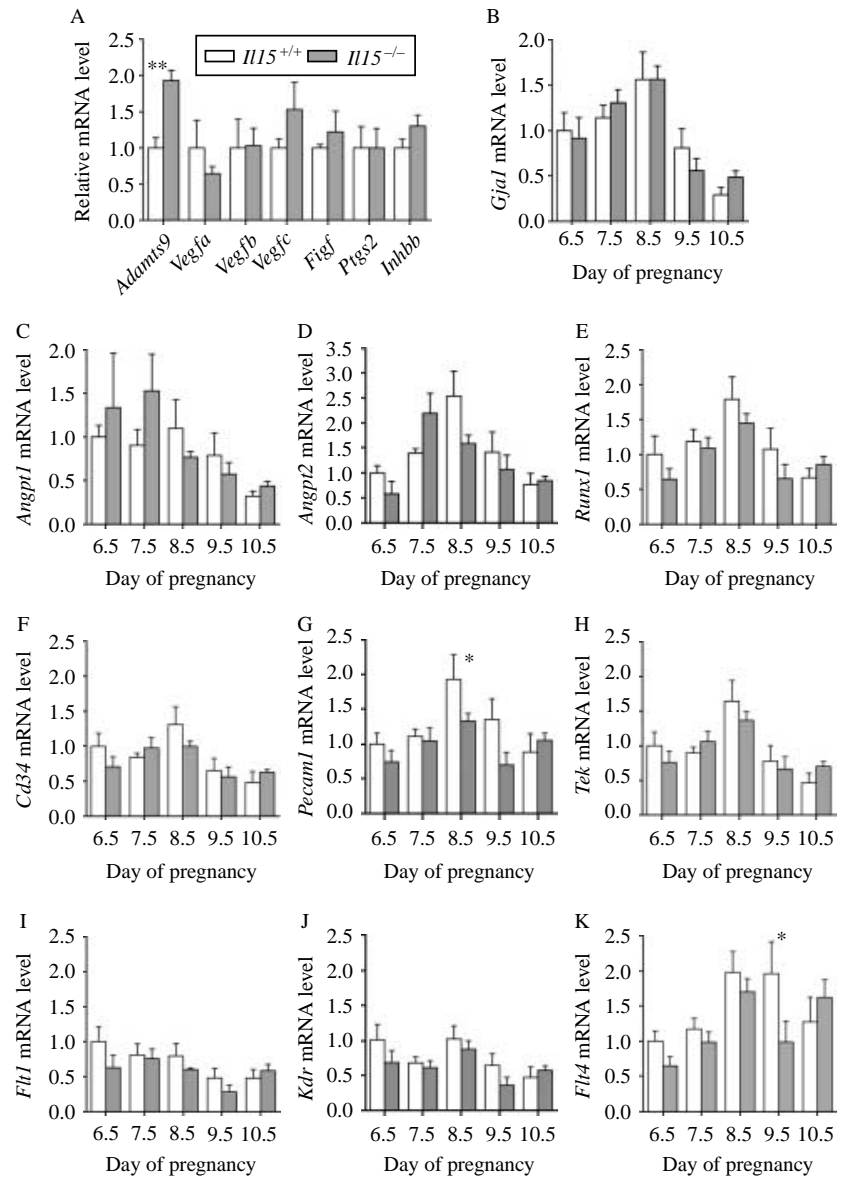

Figure 2 qRT-PCR assessment of the expression of genes potentially involved in angiogenesis or vascular markers in the uterus. (A) Relative mRNA levels in IS tissue from day 7.5 pregnant $/ 115^{+/+}$and $/ 115^{-/-}$ mice. Relative mRNA levels in IS tissues from $/ 115^{+/+}$and $/ 115^{-/-}$ mice on days 6.5-10.5 of pregnancy for (B) Gja1, (C) Angpt1, (D) Angpt2, (E) Runx1, (F) Cd34, (G) Pecam1, (H) Tek, (I) Flt1, (J) Kdr, and (K) Flt4. Bars represent the mean \pm s.E.M. $(n=4)$ and statistically significant difference in mRNA levels is denoted by asterisks $\left({ }^{*} P<0.05\right.$, $* * P<0.01)$.

\section{Angiogenesis and vascular density changes during decidualization}

Although it is clear that the characteristic of the spiral arteries by mid-pregnancy in mice depends on the presence of uNK cells, it is not solidly established that these cells play a role in angiogenesis of the uterus during decidualization. We speculated that vascular density and endothelial cell proliferation does not differ between the IS tissues of $/ 115^{+/+}$and $/ 115^{-/-}$mice given the results of the microarray and qRT-PCR analyses above. To assess this, we measured vascular density and endothelial cell proliferation in the IS tissues of $1 / 15^{+/+}$and $1 / 15^{-/-}$ mice on days 6.5, 7.5, and 8.5 of pregnancy. As shown in Fig. $3 \mathrm{~A}$ and $\mathrm{B}$, we used CD34 staining to assess the localization and numbers of endothelial cells. We also used bromodeoxyuridine (BrdU) to identify those endothelial cells undergoing proliferation. We assessed three different regions including the antimesometrial (AM) region as well as the central (CM) plus lateral (LM) mesometrial regions (Fig. $3 \mathrm{~A}$ and $\mathrm{B}$ ). There was no effect $(P>0.05)$ of genotype on endothelial cell density for each day examined in the CM (Fig. 3C), LM (Fig. 3D) or AM (Fig. 3E) areas of the endometrium. Similar findings were found for endothelial cell proliferation (Fig. 3F-H) except for the AM region in day $8.5 / / 15^{-/-}$mice where endothelial cells were not undergoing proliferation while a few were in the $/ 115^{+/+}$mice.

\section{Expression of genes involved in proteolysis}

Many of the differentially expressed genes found in the microarray work are involved in proteolysis. So we verified the differential expression of several of these genes. Cathepsins are serine proteases, some of which have been shown to be expressed in uNK cells (Croy et al. 2010). The microarray results indicated a significant $(P<0.05)$ decrease in cathepsin G $(C t s g)$ and cathepsin $\mathrm{w}(\mathrm{Ctsw})$ expression in the IS tissue of day $7.5 / / 15^{-/}$mice. As determined by qRT-PCR, we found 

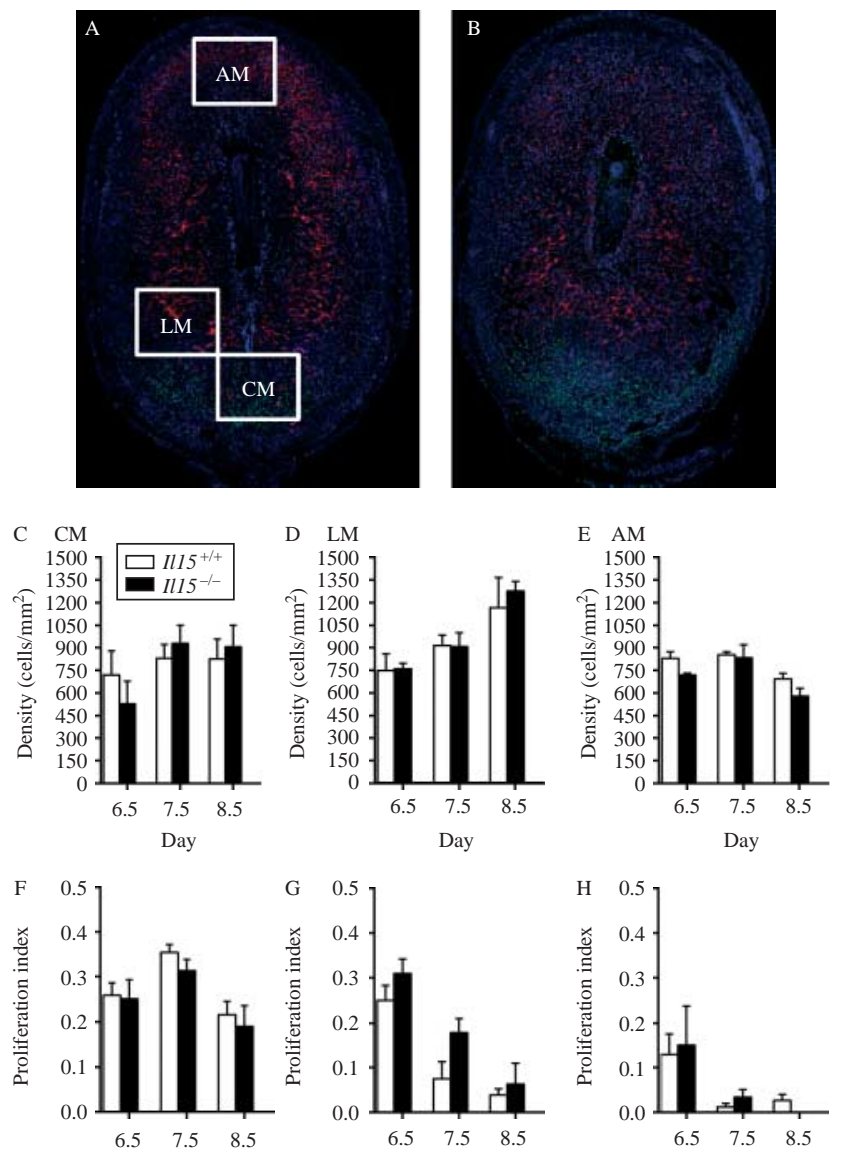

Day

Day

Day

Figure 3 Assessment of endothelial density and proliferation in the antimesometrial (AM), central mesometrial (CM), and lateral mesometrial (LM) regions of the endometrium of IS tissues of $1 / 15^{+/+}$ and $I / 15^{-1-}$ mice during decidualization on days 6.5-9.5 of pregnancy. Photomicrographs of sections from IS tissue of (A) $1 / 15^{+/+}$ and (B) $1 / 15^{-1-}$ mice stained for CD34 (red fluorescence), BrdU (green fluorescence), and counterstained nuclei (DAPI, blue fluorescence). Endothelial cell density in (C) CM, (D) LM, and (E) AM areas on days 6.5-8.5 of pregnancy. Endothelial cell proliferation in (F) CM, (G) LM, and $(\mathrm{H}) \mathrm{AM}$ areas on days $6.5-8.5$ of pregnancy. Bars represent the mean \pm S.E.M. $(n=4)$.

the Ctsg mRNA levels were significantly $(P<0.05)$ greater in IS compared with NIS tissues on days 7.58.5 of pregnancy from $1 / 15^{+/+}$mice (Fig. 4A). Ctsg mRNA levels were significantly $(P<0.05)$ greater in the IS tissue of $I / 15^{+/+}$mice compared with that of $I / 15^{-/-}$ mice on days $5.5,6.5,7.5$, and 8.5 by $\sim 40-, 200-, 600-$ and 2000-fold respectively (Fig. 4B). Also known to be expressed in NK cells (Wex et al. 2001), Ctsw mRNA levels differed significantly $(P<0.05)$ between NIS and IS tissues only on day 8.5 (Fig. 4C). However, Ctsw mRNA levels were significantly $(P<0.05)$ greater in the IS tissue of $I / 15^{+/+}$mice compared with that of $1115^{-/-}$mice on days $5.5,6.5,7.5$, and 8.5 by $~ 30-, 15-, 19$ - and 34 -fold respectively (Fig. 4D). Granzymes are another group of serine proteases, some of which have been shown to be expressed in uNK cells (Allen \& Nilsen-Hamilton 1998).

The mRNA levels of several granzymes including granzyme D (Gzmd), E (Gzme), F (Gzmf), and G (Gzmg) were verified to be expressed at a significantly $(P<0.001)$ greater level in day 7.5 IS tissues from IL15 $5^{+/+}$compared with that of $1115^{-/-}$mice (Fig. 4E). Finally, expression of two protease genes, HtrA serine peptidase 1 (Htra1) and prolylcarboxypeptidase/angiotensinase $\mathrm{C}(\operatorname{Prcp})$, was significantly $(P<0.05)$ greater in the IS tissues from $I / 15^{+9+}$ and $I / 15^{-/-}$mice respectively (Fig. 4E).

\section{Expression of genes found previously to be expressed in uNK or NK cells}

Killer cell lectin-like receptor subfamily D, member 1 (KIrd1; Soderstrom et al. 1997, Verma et al. 1997, King et al. 2000, McGrath et al. 2009), Klrg1 (Li et al. 2009), natural killer cell group 7 (Nkg7), perforin (Prf1) (Parr et al. 1990), secreted phosphoprotein 1 (Spp1; Herington \& Bany 2007a), and tumor necrosis factor receptor superfamily member 9 (Tnfrsf9; Eckstrum \& Bany 2011) genes have previously been shown to be expressed in uNK or NK cells. Since uNK cells are missing from the IS tissues of $/ 115^{-/-}$mice (Barber \& Pollard 2003, Croy et al. 2003 b) and the microarray analysis identified the above-mentioned genes to be differentially expressed, we verified differential expression of these genes using qRT-PCR in the IS tissue from day 7.5 pregnant $/ 115^{-/-}$ compared with $/ / 15^{+/+}$mice (Fig. $4 \mathrm{E}$ ).

\section{Advillin expression}

Since advillin (AVIL) is involved in cell morphogenesis (Shibata et al. 2004) and its expression was only seen in the IS tissue of $1 / 15^{+/+}$mice in the microarray analysis, we further characterized its expression in the uterus. Avil mRNA levels significantly $(P<0.05)$ increased in the IS compared with NIS tissues of the uteri of $1115^{+/+}$mice on days $6.5,7.5$, and 8.5 of pregnancy during decidualization (Fig. 5A). Previously, we found uNK cell numbers are significantly decreased in uteri undergoing bead-induced decidualization (BID) by days 7.5 and 8.5 (Herington \& Bany 2007b), but in a recent microarray study, differences in Avil mRNA levels were not seen between the decidua and deciduoma on day 7.5 (McConaha et al. 2011). Therefore, we examined Avil mRNA levels in the IS tissue of pregnant mice and BID of pseudopregnant mice on days 4.5-8.5. There was a significant $(P<0.05)$ decrease in Avil mRNA levels in BID compared with IS tissues only on day 8.5 (Fig. 5B). Next, we assessed the differential expression of Avil between the IS tissues from $/ 115^{+/+}$and $/ 115^{-/-}$mice on days 4.5-8.5 of pregnancy. As shown in Fig. 5C, Avil mRNA levels were significantly $(P<0.05)$ greater in the IS tissues of $1 / 15^{+/+}$compared with $/ 115^{-/-}$mice on days $6.5,7.5$, and 8.5 of pregnancy. Finally, to localize 

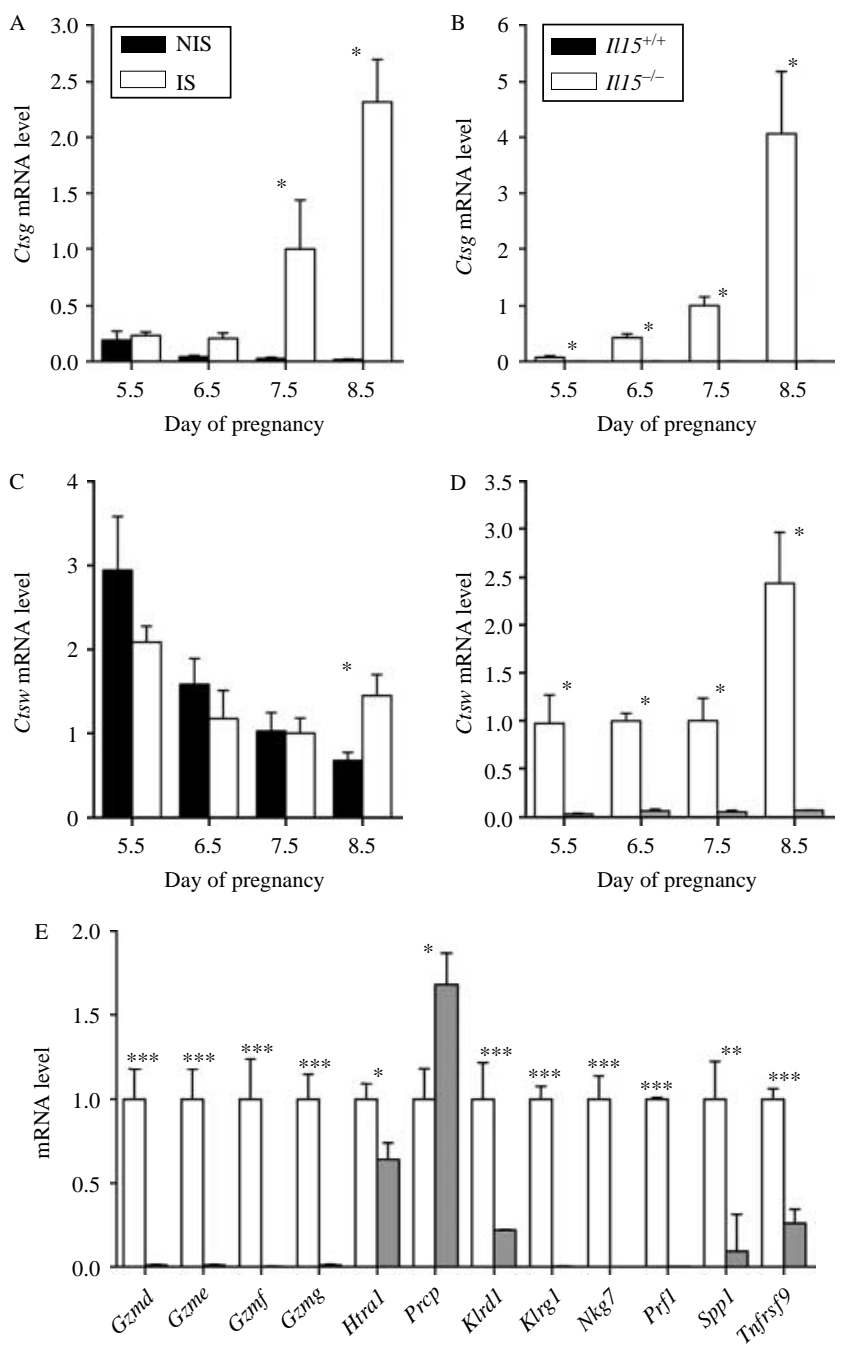

Figure 4 qRT-PCR assessment of Ctsg and Ctsw expression in the pregnant mouse uterus. Relative Ctsg and Ctsw mRNA levels in non-implantation (NIS) and implantation (IS) segments of the uterus (A and B) or IS segments from $/ / 15^{+/+}$and $/ / 15^{-/-}$mice (C and D) on days 5.5-8.5 of pregnancy. (E) Relative mRNA levels of 12 genes in the IS tissues of day 7.5 pregnant $/ 115^{+/+}$and $/ 115^{-/-}$mice. Bars represent the mean \pm S.E.M. $(n=4-6)$ and statistically significant difference in mRNA levels is denoted by asterisks $\left({ }^{*} P<0.05\right.$, $* * P<0.01, * * * P<0.001)$.

where Avil is expressed, we carried out in situ hybridization on sections from day 7.5 (Fig. 5D and E) and day 8.5 (Fig. 5F and G) pregnant uteri from $/ / 15^{+/+}$ mice. Avil mRNA was localized to a subgroup of cells in the mesometrial decidual region. To determine if this expression was localized to uNK cells, we used DBA lectin histochemistry coupled with Avil in situ hybridization. DBA lectin stains a subset of uNK cells in the mouse uterus during decidualization. As shown in Fig. 5H-J, the Avil mRNA was localized to a subset of DBA-positive uNK cells in the mesometrial decidua of day 7.5 mice. Not all DBA lectin-positive cells were Avil
mRNA positive, but all Avil mRNA-positive cells were DBA lectin positive. Finally, sections from $/ 115^{-/-}$mice showed neither DBA-positive uNK cells nor Avil mRNApositive cells in the mesometrial decidua (Fig. 5K).

\section{Small proline-rich protein $2 D$ expression}

The expression of the large family of small proline-rich protein 2 (Sprr2) genes has been examined in the mouse endometrium and most of them are estrogen-regulated genes (Hong et al. 2004). Our microarray data suggested that Sprr2d mRNA levels are significantly $(P<0.05)$ reduced in the IS tissue of day 7.5 pregnant uteri from $1 / 15^{-/-}$mice compared with those from $/ / 15^{+/+}$mice. To characterize the expression of the Sprr2d gene during decidualization, we examined expression in the uterus on days 4.5-8.5 of pregnancy. As shown in Fig. 6A, Sprr2d mRNA levels significantly $(P<0.05)$ increased in IS compared with NIS tissues from the uteri of pregnant $1 / 15^{+/+}$mice on days $6.5,7.5$, and 8.5 of pregnancy by $\sim 16-, 29-$ and 214-fold respectively. Next, we examined the differences in Sprr2d mRNA levels in the IS tissues from $/ 115^{+/+}$compared with $/ / 15^{-/-}$mice. As shown in Fig. 6B, mRNA levels were significantly greater in the IS tissues from $/ 115^{+/+}$compared with $/ 115^{-9-}$ mice on days 7.5-8.5. We then carried out in situ hybridization to localize Sprr2d mRNA. As shown in Fig. 6C, Sprr2d mRNA was localized to the AM decidua in the IS tissue of $1 / 15^{+/+}$mice. Some mRNA was also localized to the same area in $/ / 15^{-/-}$mice, but to a lesser extent (Fig. 6C).

\section{Degenerative spermatocyte homolog 2 expression}

Our microarray data suggested that degenerative spermatocyte homolog 2 (Degs2) mRNA levels are significantly reduced in the IS tissue of day 7.5 pregnant uteri from $1 / 15^{-1-}$ mice compared with those from $1 / 15^{+/+}$mice. Since the levels of one of the products of DEGS2 action, ceramide, increases in the uterus during implantation and may play a role in decidualization (Kaneko-Tarui et al. 2007), we characterized the expression of Degs2 in the uterus during implantation. As shown in Fig. 6D, Degs2 mRNA levels were significantly $(P<0.05)$ greater in NIS compared with IS tissue from the uteri of pregnant $/ / 15^{+/+}$mice on days 5.5 and 6.5 of pregnancy. Next, we examined the differences in Degs2 mRNA levels in IS tissues from $1 / 15^{+/+}$compared with $/ 115^{-1-}$ mice. As shown in Fig. 6E, mRNA levels were significantly greater in the IS tissues from $/ 115^{+/+}$compared with $/ 115^{-/-}$mice on days 7.5 and 8.5 of pregnancy. Finally, we carried out in situ hybridization to localize Degs2 expression in the uteri on day 7.5 of pregnancy. As shown in Fig. 6F, Degs 2 mRNA was found in mesometrial decidual cells just adjacent to the conceptus in IS tissue from $/ / 15^{+/+}$ mice, but not in that of $1 / 15^{-1-}$ mice. 

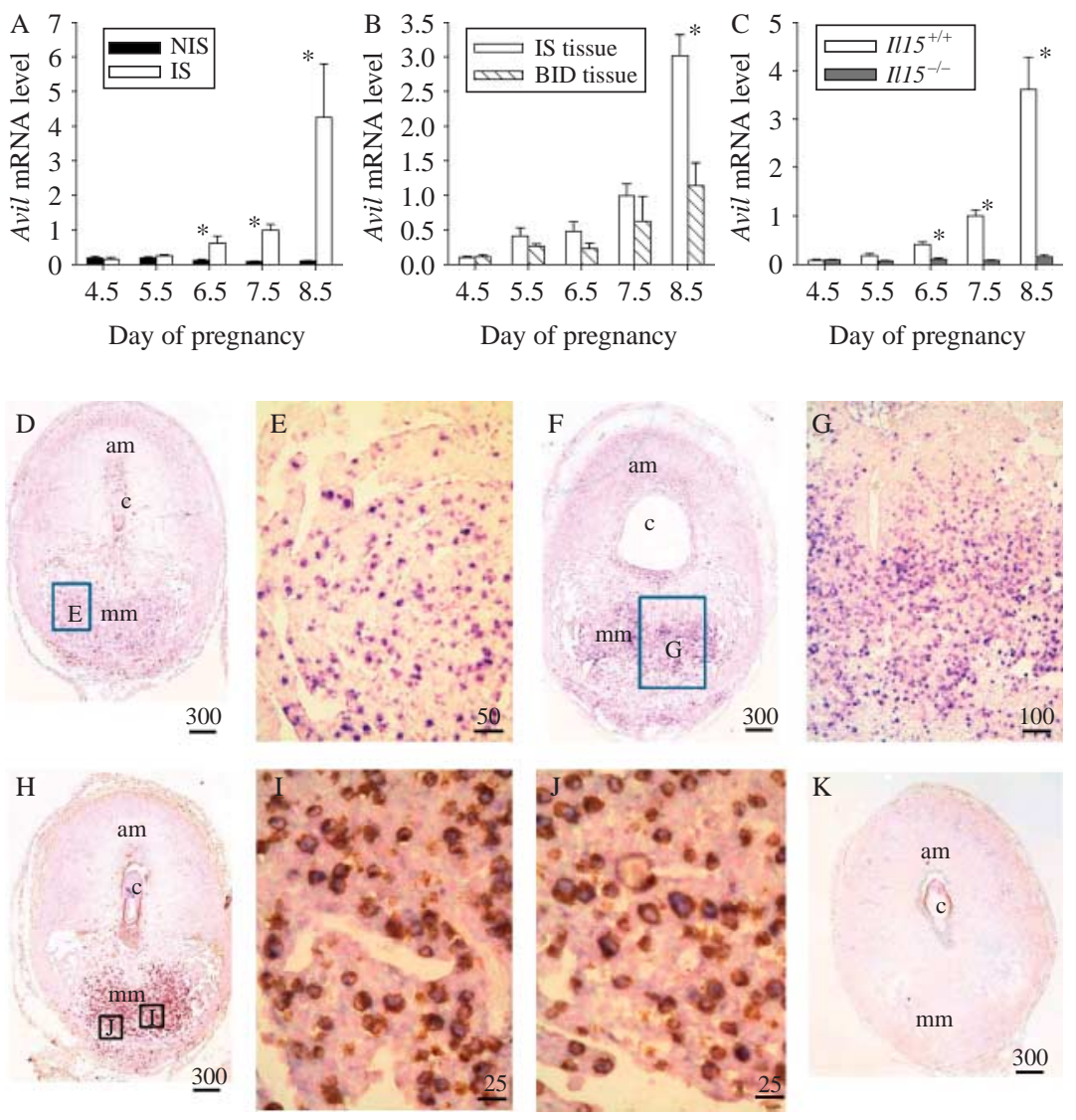

$\mathrm{K}$

\section{Cytokine-induced apoptosis inhibitor 1 expression}

Our microarray data suggested that cytokine-induced apoptosis inhibitor 1 (Ciapin1) mRNA levels are significantly reduced in the IS tissue of day 7.5 pregnant uteri from $1 / 15^{-1-}$ mice compared with those from $1 / 15^{+/+}$mice. Since RAS plays a role in decidualization (Cho et al. 2011) and Ciapin1 operates downstream of the receptor tyrosine kinase-Ras signaling pathway (Hao et al. 2006), we characterized Ciapin1 mRNA levels in the mouse uterus during decidualization. As shown in Fig. 6G, Ciapin1 mRNA levels increased in IS compared with NIS tissues from the uteri of pregnant $1 / 15^{+/+}$mice on days $6.5-8.5$ of pregnancy. Next, we examined the differences in Ciapin1 mRNA levels in the IS tissues from $/ / 15^{+/+}$compared with $/ / 15^{-/-}$mice. As shown in Fig. 6H, mRNA levels were significantly greater in the IS tissues from $1 / 15^{+/+}$compared with $/ 115^{-/-}$ mice on days 5.5-8.5 of pregnancy. Finally, we carried out in situ hybridization to localize Ciapin1 expression in the uteri on day 7.5 of pregnancy. As shown in Fig. 6l, Ciapin1 mRNA was found in mesometrial decidual cells just adjacent to the ectoplacental cone and in the AM decidua adjacent to the myometrium in IS tissue from $1 / 15^{+/+}$mice. A similar signal for Ciapin1 mRNA in tissues from $/ 115^{-1-}$ mice was only seen in the AM stromal cells in IS tissues.
Figure 5 Avil expression in the mouse uterus during decidualization and its localization to uNK cells using qRT-PCR and in situ hybridization. (A) Relative Avil mRNA levels between NIS and IS tissues of pregnant mouse uterus on days 4.5-8.5 of pregnancy. (B) Relative Avil mRNA levels between IS tissue and BID tissue of the mouse uterus on days 4.5-8.5 of pregnancy and pseudopregnancy respectively. (C) Relative Avil mRNA levels between IS tissues from $/ 115^{+/+}$and $/ 115^{-/-}$mice on days 4.5-8.5 of pregnancy. Bars represent the mean \pm S.E.M. $(n=3-4)$ and $*$ denotes a statistically significant $(P<0.05)$ difference between bars on a given day. Localization of Avil mRNA in IS tissue of $1115^{+/+}$mice on ( $\mathrm{D}$ and $\mathrm{E}$ ) day 7.5 and ( $\mathrm{F}$ and $\mathrm{G}$ ) day 8.5 of pregnancy. Localization of Avil mRNA and DBA lectin-positive uNK cells in IS tissue of $(\mathrm{H}-\mathrm{J})$ $1 / 15^{+/+}$and $(\mathrm{K}) / / 15^{-/-}$mice on day 7.5 of pregnancy. Scale bars are in microns.

\section{Annexin A8 expression}

Annexin A8 (Anxa8) encodes a protein that plays a role in late endosome organization and function (Goebeler et al. 2008). Our microarray data suggested that Anxa8 mRNA levels are significantly reduced in the IS tissue of day 7.5 pregnant uteri from $1 / 15^{-/-}$ mice compared with those from $1 / 15^{+/+}$mice. To characterize the expression of this gene during decidualization, we examined its expression in the uterus on days 3.5-8.5 of pregnancy. As shown in Fig. 7A, Anxa8 mRNA levels increased in IS compared with NIS tissues from the uteri of pregnant $/ 115^{+/+}$mice on days 5.5-8.5 of pregnancy. Next, we examined the differences in Anxa8 mRNA levels in the IS tissues from $1 / 15^{+/+}$ compared with those from $1 / 15^{-1-}$ mice. As shown in Fig. 7B, mRNA levels were significantly greater in IS tissues from $1 / 15^{+/+}$compared with those from $/ 115^{-/-}$ mice on day 7.5 .

\section{RAP1 GTPase-activating protein expression}

Although little is known about the function of RAP1 GTPase-activating protein (Rap1gap) expression in the uterus during implantation, we characterized its expression in the uterus since the microarray data suggested that its mRNA levels are significantly reduced 

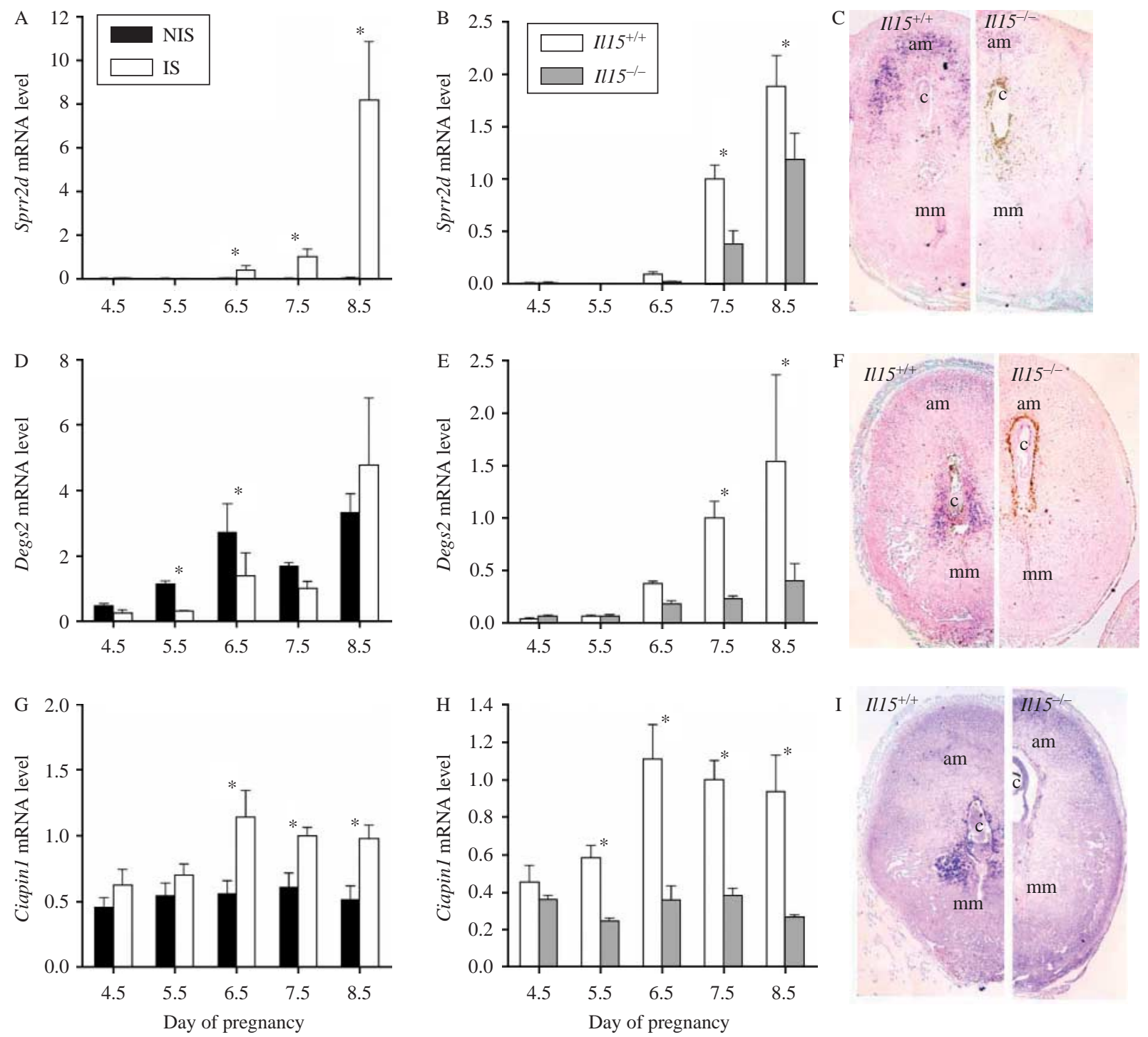

Figure 6 (A-C) Sprr2d, (D-F) Degs2, and (G-I) Ciapin1 expression and localization in the mouse uterus during decidualization using qRT-PCR and in situ hybridization respectively. (A, D and G) Relative mRNA levels between NIS and IS tissues of pregnant mouse uterus on days 4.5-8.5 of pregnancy. (B, E and H) Relative mRNA levels between IS tissues from $/ 115^{+/+}$and $/ 115^{-/-}$mice on days $4.5-8.5$ of pregnancy. Bars represent the mean \pm s.E.M. $(n=3-4)$ and * denotes a statistically significant $(P<0.05)$ difference between bars on a given day. (C, F and I) Localization of mRNA in IS tissue of $/ 115^{+/+}$(left panel) and $/ / 15^{-/-}$(right panel) mice on day 7.5 of pregnancy.

in the IS tissue of day 7.5 pregnant uteri from $1 / 15^{-1-}$ mice compared with those from $/ 115^{+/+}$mice. As shown in Fig. 7C, relative Rap1gap mRNA levels significantly $(P<0.05)$ increased in IS compared with NIS tissues on days 6.5-9.5 of pregnancy. As shown in Fig. 7D, mRNA levels were also significantly $(P<0.05)$ greater in IS tissues from $/ 115^{+/+}$compared with those from $I / 15^{-/-}$ mice on these days.

\section{Zinc finger and BTB domain containing 32 expression}

Zinc finger and BTB domain containing 32 (Zbtb32) is a transcriptional repressor that negatively regulates T-cell activation (Kang et al. 2005). Although little is known about the function of Zbtb32 expression in the uterus during implantation, we characterized its expression in the uterus since the microarray data suggested that its mRNA levels are significantly reduced in the IS tissue of day 7.5 pregnant uteri from $1 / 15^{-1-}$ mice compared with those from $/ 115^{+/+}$mice. Relative mRNA levels of Zbtb32 were found to be significantly $(P<0.05)$ increased in IS compared with NIS tissues of the pregnant uterus on days $6.5,7.5$, and 8.5 of pregnancy by an average of 7-, 15-, and 35-fold respectively (Fig. 7E). As shown in Fig. 7F, mRNA levels were also significantly $(P<0.05)$ greater in the IS tissues from $1 / 15^{+/+}$compared with those from $1 / 15^{-1-}$ mice on days $6.5-8.5$. 

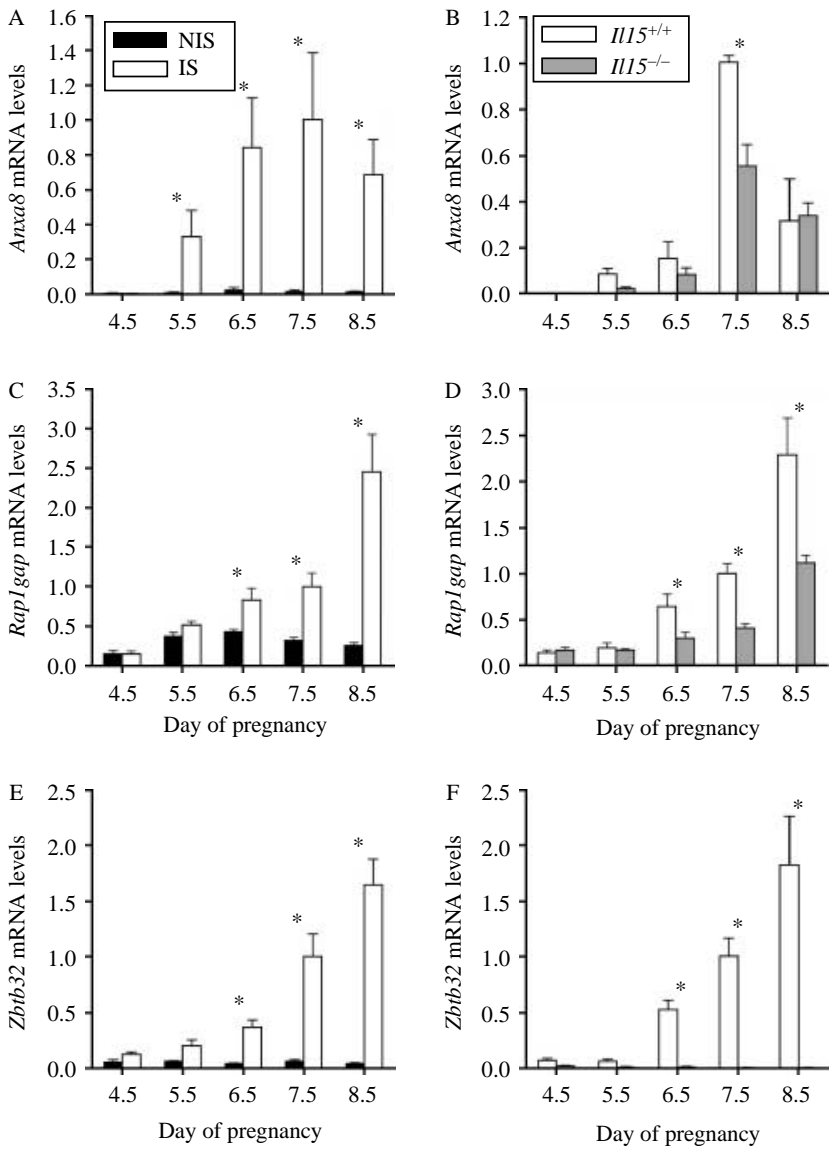

Figure 7 (A and B) Anxa8, (C and D) Rap1gap, and (E and F) Zbtb32 expression and localization in the mouse uterus during decidualization using qRT-PCR and in situ hybridization respectively. (A, C and E) Relative mRNA levels between NIS and IS tissues of pregnant mouse uterus on days 4.5-8.5 of pregnancy. (B, D and F) Relative mRNA levels for IS tissue from $/ / 15^{+/+}$and $/ / 15^{-/-}$mice on days $4.5-8.5$ of pregnancy. Bars represent the mean \pm S.E.M. $(n=3-4)$ and $*$ denotes a statistically significant $(P<0.05)$ difference between bars on a given day.

\section{Further independent verification of microarray data}

We verified the differential expression of several additional genes using qRT-PCR. As shown in Fig. 8, we attempted to verify differential levels of mRNAs between the IS tissues from $1 / 15^{+/+}$and $1 / 15^{-/-}$mice for an additional 18 genes. As shown in Fig. 8A, we verified a significantly greater $m R N A$ level in the IS tissue from $/ 115^{+}++$mice for coronin actin binding protein $1 \mathrm{~A}$ (Coro1a, $P<0.05)$, diamine oxidase-like protein 2 $($ Dox $12, \quad P<0.05)$, glycerophosphodiester phosphodiesterase domain containing $3(G d p d 3, P<0.005)$, NECAP endocytosis associated 2 (Necap2, $P<0.001$ ), neuromedin $U(N m u, P<0.05)$, platelet-derived growth factor receptor-like $(P d g f r l, P<0.001)$, phospholipase $C$ gamma 1 ( $P l c g 1, P<0.001)$, proline-serine-threonine phosphatase-interacting protein 1 (Pstpip1, $P<0.001$ ), selectin platelet ligand (Selplg, $P<0.001$ ), serine peptidase inhibitor Kazal type 2 (Spink2, $P<0.05)$, chemokine (C motif) ligand $1\left(X_{C} / 1, P<0.001\right)$, and RIKEN cDNA
6330403K07 (6330403KO7Rik, P<0.05). As shown in Fig. $8 \mathrm{~B}$, we verified a significantly greater mRNA level in the IS tissue from $/ / 15^{-/-}$compared with that from $1 / 15^{+/+}$mice for GTP cyclohydrolase 1 (Gch1, $\left.P<0.05\right)$, glutathione peroxidase $2(G p \times 2, P<0.001)$, MAP7 domain containing 2 (Mtap $7 d 2, P<0.001$ ), regulator of G-protein signaling 5 (Rgs5, $P<0.05)$, calcium binding protein A9 (S100a9, $P<0.05$ ), short coiled-coil protein (SCOC, $P<0.005)$, Spink3 $(P<0.05)$, and RIKEN CDNA 6720422M22 (6720422M22Rik, $P<0.01)$.

\section{Discussion}

The developing decidual tissue provides a critical nutritive environment for the conceptus before the establishment of the functional placenta. The major immune cells present in the uterus during decidualization are uNK cells and they are present in the mesometrial decidua during decidualization (Zhang et al. 2009). However, the role of the immune system in the process of decidualization is currently not well understood. The availability of several genetic models, where uNK cells are absent during pregnancy, makes such an assessment possible. //15-deficient mice lack uNK cells in the uterus during implantation and this genetic model had been used previously to study uNK cell function in the uterus during implantation in mice (Ashkar et al. 2003, Barber \& Pollard 2003, Croy et al. 2003a). This work clearly supports a role for uNK cells in 'maintenance of decidual integrity' based on the observation that the decidual basalis after mid-pregnancy is acellular in uNK-deficient mice (Ashkar et al. 2003). Notably, the use of this and other similar models of UNK cell deficiency has not revealed if uNK cells play a role in decidualization itself, which occurs in the uterus during the 4-5 days of pregnancy leading up to mid-pregnancy. Thus, the present study was initially undertaken to determine the differences in uterine gene expression in IS tissues between $/ 115^{+/+}$and $/ / 15^{-/-}$mice during decidualization using whole-genome Illumina BeadArray analysis. The microarray results suggested that 300 genes were differentially expressed and the differential mRNA levels of approximately one-sixth of these were verified independently using qRT-PCR. Interestingly, the present study did not reveal any differential expression of key genes known to play roles in endometrial stromal cell decidualization or of genes that are decidual cell markers. Therefore, the results of this study support the hypothesis that uNK cells do not play a critical role in decidualization and the loss of decidual integrity seen after mid-pregnancy in $1 / 15^{-1-}$ mice is not due to a defect in decidual cell differentiation.

Decidualization involves a rapid growth of the endometrial tissue mass and is accompanied by angiogenesis. Several genetic models, including $l / 15^{-1-}$, have established a critical role for uNK cells in the spiral arteriole modification seen after mid-pregnancy. 


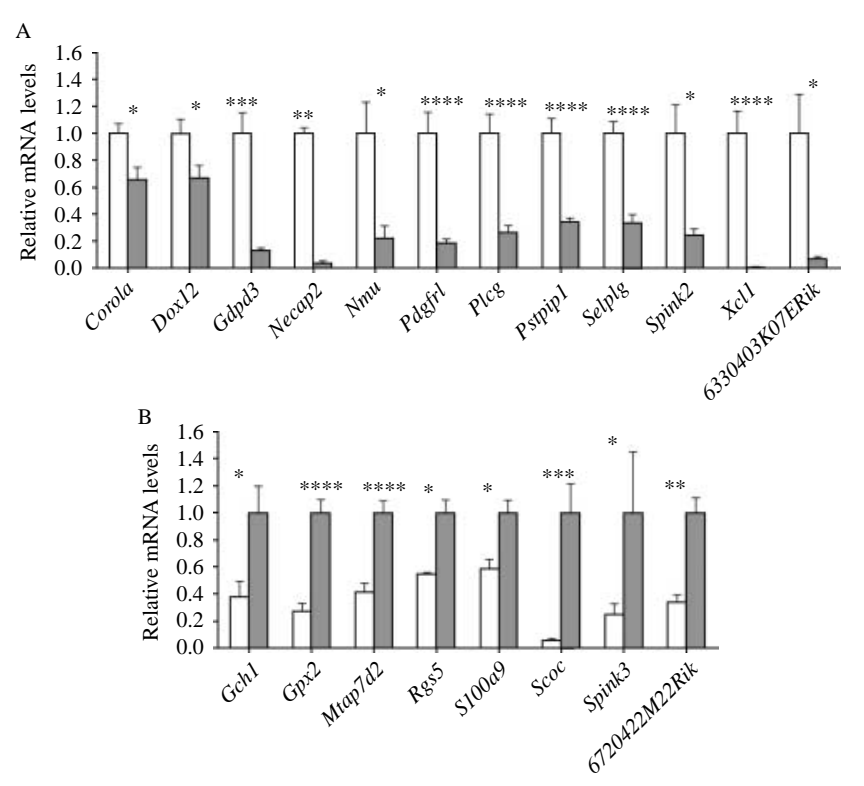

Figure 8 Independent verification of the differential expression of 20 additional genes using qRT-PCR. Relative mRNA levels of 12 and 8 genes found to be expressed at higher levels in IS tissue of (A) $1115^{+/+}$ and (B) $1 / 15^{-1-}$ mice by microarray analysis. Bars represent the mean \pm S.E.M. $(n=3-6)$ and statistically significant difference in mRNA levels is denoted by asterisks $\left({ }^{*} P<0.05,{ }^{* *} P<0.01,{ }^{* * *} P<0.005\right.$, and $* * * * P<0.001)$.

Further, it has been speculated that uNK cells may play a critical role in endometrial angiogenesis during decidualization or implantation in rodents and humans due to the observations that they are a source of angiogenic factors (Lash et al. 2010, Zhang et al. 2011). The expression of several genes such as Vegfa (Halder et al. 2000), Ptgs2 (Lim et al. 1997, Matsumoto et al. 2002), Gja1 (Laws et al. 2008), Angpt2 (Matsumoto et al. 2002, Hess et al. 2006), Tie2 (Matsumoto et al. 2002), Flt1, and Kdr (Chakraborty et al. 1995, Douglas et al. 2009) is believed to play a role in angiogenesis in the endometrium during decidualization. Further, several endothelial vascular endothelial cell markers such as Flt4 (Douglas et al. 2009), Cd34 (Morison et al. 2007), Pecam1 (Ma et al. 1997), Adamts9 (Jungers et al. 2005), and Inhbb (McConaha et al. 2011) have been shown to be expressed in the endometrial endothelial cells during decidualization. Notably, with the exception of Adamts9 which is an anti-angiogenic factor, none of the other genes were differentially expressed in IS tissues between $1 / 15^{+/+}$and $/ 115^{-/-}$mice. This included genes that encode angiogenic factors such as Vegfa and Vegfc which have previously been shown to be expressed by mouse and human uNK cells respectively (Wang et al. 2000, 2003, Lash et al. 2006). Therefore, uNK cells appear not to be the major source of Vegfa expression in the mouse uterus during decidualization. Finally, vascular morphometric analysis in the present study revealed very little difference in the endothelial cell densities and endothelial cell proliferation indices between IS tissues from $1 / 15^{+/+}$and $/ 115^{-/-}$mice during decidualization. Taken together, the data of this study suggest that uNK cells do not play a major role in angiogenesis or neovascularization in the endometrium during decidualization. Therefore, the lack of decidual integrity in genetic models that lack uNK cells is likely not due to decreased angiogenesis and impaired blood flow to the developing decidua during decidualization.

The cathepsin family of genes encodes either serineor cysteine-proteases found in lysosomes within cells. Previous work has shown that the cathepsin D gene $(C t s d)$ is expressed in mature uNK cells in the mouse uterus by mid-pregnancy (Croy et al. 2010). However, whether uNK cells are a major source of other cathepsins remains to be determined. Therefore, it was interesting that the present study did not reveal a significant decrease in Ctsd expression in the IS tissue of IL15 mice but did for Ctsg and Ctsw. CTSG is found in neutrophil lysozymes and upon secretion it can enhance the activity of interleukin-8, decrease the bioavailability of interleukin-6, activate cytokines (interleukin-1 beta, tumor necrosis factor alpha), and activate certain receptors (epidermal growth factor, proteinase activated receptors) (Conus \& Simon 2010). Although it still needs to be proven, we speculate that the reduction of Ctsg expression found in the IS tissue of $I / 15^{-1-}$ mice may be due to a decrease in neutrophil numbers. Ctsw is exclusively expressed in NK cells as well as CD8positive $\mathrm{T}$ cells but is not involved in cytotoxicity or interferon gamma production (Stoeckle et al. 2009). Unlike Ctsg, where there is an increased expression in IS tissues during decidualization, Ctsw expression in pregnancy appears to be complex because expression levels are similar in NIS and IS tissues until day 8.5. The present study shows that Ctsg expression and Ctsw expression in the mouse uterus during decidualization are both dependent on IL15 and further work to localize expression and determine their function in the uterus during this process is warranted.

Several genes known to be expressed by uNK cells of the uterus during the establishment of pregnancy or in NK cells in general were expected to be expressed at significantly lower levels in IS tissue from $1 / 15^{-1-}$ mice compared with those of $1 / 15^{+/+}$mice. This included some granzymes (Allen \& Nilsen-Hamilton 1998) and killer cell lectin-like receptor (Soderstrom et al. 1997, Verma et al. 1997, King et al. 2000, McGrath et al. 2009) genes along with Ctsd (Croy et al. 2010), Prf1 (Parr et al. 1990), Spp1 (Herington \& Bany 2007a), and Tnfrsf9 (Eckstrum \& Bany 2011). Such a result was expected as uNK cells would be a major source of this expression in the uterus during decidualization. Indeed, many of these genes (but not all) were actually shown to be differentially expressed. However, it is notable that of the four genes examined further using in situ hybridization, only Avil was shown to be expressed in uNK cells. 
Since expression of Sprr2d, Degs2, and Ciapin1 was not found in uNK cells, the control of their expression by IL15 may be more complex. Whether or not all of the other genes found to be differentially expressed at higher levels in IS tissues from $/ / 15^{+/+}$compared with $/ 115^{-/-}$ mice are expressed in uNK cells will require further work on each gene.

AVIL is an intracellular protein that belongs to the gelsolin superfamily of actin regulatory proteins (Silacci et al. 2004). The present study demonstrated that the expression of Avil in the endometrium during decidualization is located to uNK cells. Although the precise function of AVIL in UNK cell biology is not understood at present, it is known to interact with a protein called scavenger receptor member 1 (SCARF1; Shibata et al. 2004). AVIL is believed to play a role in cell morphogenesis through its interaction with SCARF1 (Shibata et al. 2004). Since uNK cells undergo a great deal of changes in cell size and shape as they mature in the endometrium during decidualization ( $\mathrm{He}$ et al. 1999), we speculate that AVIL may be playing a role in uNK maturation. However, SCARF1 is also responsible for binding to and internalization of extracellular heat shock proteins, which may be important in cell signaling and immunity (Calderwood et al. 2007a, 2007b). Thus, the precise function of AVIL in the endometrium during decidualization remains to be determined.

Ceramide levels increase in the uterus during decidualization where it may play a role in apoptosis. Apoptosis occurs in the epithelia and stromal compartments of the endometrium during implantation, but little is known on how this is regulated (Pampfer \& Donnay 1999, Joswig et al. 2003). Ceramide levels are increased by a diverse number of stress stimuli and ceramide causes suppression in cell growth and promotion of apoptosis (Ruvolo 2003). It appears that the balance of ceramide production and breakdown pathways seems to favor an increased accumulation in the uterus since ceramide levels in the mouse uterus increase during decidualization (Kaneko-Tarui et al. 2007). One major pathway of ceramide production is via serine where the last step involves the dihydroceramide $\Delta 4$-desaturase and C-4 hydroxylase activities of DEGS2, which produces ceramide from dihydroceramide (Enomoto et al. 2006). The present study shows that Degs2 mRNA is localized to the mesometrial decidua and its level is significantly reduced in the IS site of $1 / 15^{-1-}$ mice compared with that of $/ / 15^{+/+}$mice. Therefore, it is possible that ceramide-mediated apoptosis of the mesometrial decidua may be occurring to make place for the developing placenta. Notably, we also characterized the expression of another apoptosis-related gene in this study, Ciapin1. Ciapin1 encodes a protein originally called anamorsin that also plays roles in apoptosis as a downstream effector of RAS-signaling in the uterus (Hao et al. 2006). Ciapin 1 was also expressed in a region similar to that of Degs2 in the mesometrial decidua. Its expression levels dramatically increased in the IS tissue during implantation. In addition, expression of Ciapin 1 in the IS tissue of $1 / 15^{-1-}$ mice was dramatically reduced during decidualization compared with that of $1 / 15^{+/+}$mice. Therefore, it appears that the expression of both Degs2 and Ciapin1 in the uterus is dependent on IL15. Whether or not this involves the loss of uNK cells or occurs through another mechanism remains to be studied further, as do the potential roles of these genes in apoptosis in the mesometrial decidua during implantation.

In conclusion, this study provides the identity of many genes whose expression in the uterus during decidualization is altered between $/ 115^{+/+}$and $/ 115^{-/-}$mice. However, only speculation on the potential function of many of these genes in the uterus during decidualization may be derived from the literature because the work was conducted on non-uterine tissues or cell types. For example, the present study shows the transcriptional repressor Zbtb32 is expressed at high levels in the IS tissues of the uterus during decidualization in $1 / 15^{+/+}$ mice and this expression is mainly lost in $/ 15^{-/-}$mice. Since it has been shown in other tissues/cells that ZBTB32 acts as a repressor of the activity of GATA transcription factors, one can speculate that it may play a similar role in the uterus. However, currently, very little is known about uterine GATA transcription factor gene expression and function in the uterine compartment during decidualization. Another example of a gene found to be differentially expressed in this study was Rap1gap. RAP1GAP is known to activate mitogenactivated or extracellular (MAP/ERK) kinase signaling cascades in other tissues/cell types by increasing the rate of GTP hydrolysis, which in turn causes the inactivation of RAP GTPases (Ika et al. 2009, Tsygankova et al. 2010). However, to the best of our knowledge, nothing is known about the function of Rap1gap expression in the uterus during decidualization. In summary, the functions of many of the other genes found to be differentially expressed in this study still remain to be determined and can only be speculated at this time. However, this study should form the basis of future research on these genes.

\section{Materials and Methods}

\section{Mice and sample collection}

All procedures involving mice were approved by the Southern Illinois University Institutional Animal Care and Use Committee. They were maintained under controlled light conditions (lights on from 0700 to $2100 \mathrm{~h}$ ) and were allowed free access to food and water. CD1 mice with a targeted deletion of the $/ / 15$ gene $\left(I / 15^{-/-}\right)$as well as wild-type $\left(/ / 15^{+/+}\right)$and $/ / 15^{-/-}$virgin females (8-12 weeks) were mated with $/ 115^{-/-}$and wild-type male CD1 mice respectively. Wild-type CD1 mice were obtained from Charles River Laboratories (Wilmington, MA, USA) and generation of the $/ / 15^{-/-}$mice on a CD1 background was previously described (Eckstrum \& Bany 2011). The morning 
a vaginal plug was detected was considered to be day 0.5 of pregnancy. These pregnant mice, all of which carried heterozygous embryos/conceptuses, were killed at 0900 h on days 4.59.5 of pregnancy. The bead-induced decidualization model was used exactly as described previously (McConaha et al. 2011).

\section{RNA isolation}

For day 4.5-8.5 uterine horns, NIS IS segments were separated. For IS segments, tissues of the conceptus (embryo and trophoblast cells) were carefully dissected out and discarded. All the remaining tissues were then pooled and considered IS segment tissue. Tissues were stored in RNA Later (Life Technologies, Grand Island, NY, USA). Total RNA was isolated using Trizol reagent as recommended by the manufacturer (Invitrogen). The RNA was then subjected to DNase digestion using Turbo DNase as recommended by the manufacturer (Ambion), followed by re-extraction with Trizol.

\section{Microarray analysis}

RNA samples isolated from the uterine tissue of day 7.5 IS segments in $1 / 15^{+/+}$and $1 / 15^{-1-}$ mice were used for the microarray analysis $(n=3)$. The RNA quality was verified using an Agilent Bioanalyzer (Agilent Technologies, Santa Clara, CA, USA) before microarray analysis as previously described (McConaha et al. 2011). Briefly, total RNA isolated from the tissue for each experiment was used to create biotin-labeled cRNA target samples $(n=3)$ using the Illumina RNA amplification kit (Applied Biosystems, Carlesbad, CA, USA). The cRNA target preparations were then hybridized to the arrays for $16-20 \mathrm{~h}$ at $55^{\circ} \mathrm{C}$, and the bound biotin-labeled targets were then detected using streptavidin-Cy3 and an Illumina Bead Array Reader with BeadStudio software (Illumina, Inc. San Diego, CA, USA). Probe data were filtered to include only those with detection scores $>0.98(P<0.02)$ for all samples. The data were then exported to Chipster for further analysis (Kallio et al. 2011). The quantile normalization (Bolstad et al. 2003) tool of Chipster, which uses the limma R package, was used to normalize the data. Significance of differential expression was determined with the Chipster tool that uses the Bioconductor package limma Empirical Bayes method (Smyth 2004). The default Benjamini-Hochberg method was used to control the false discovery rate. Differences were considered significant if the adjusted $P$ values were $<0.05$. Finally, the raw data were filtered to find probe signals which were significantly above background in all three samples from all three $1 / 15^{+/+}$or $1 / 15^{-/-}$mice. This was defined as a detection score $>0.98$, a signal level $>150$ plus an average of fourfold or greater signal above background. The lists of probes and relative signal levels were combined and annotated using the Bioconductor annaffy package of Chipster. Probes were removed from further analysis and from the lists of differentially expressed genes if they did not map to a gene or were mapped to either more than one gene or a pseudogene. Finally, the hypogeometric test for GO tool of Chipster was used to determine over- and under-represented GO terms of the list of differentially expressed genes using a cutoff of $P<0.01$ for statistical significance.

\section{qRT-PCR analysis}

qRT-PCR was carried out as described previously (McConaha et al. 2011) using the oligonucleotide primers (IDT Technologies, Coralville, IA, USA) shown in Supplementary Table 3, see section on supplementary data given at the end of this article. Briefly, High Capacity RNA-to-cDNA kits (Applied Biosystems) were used to generate the cDNA. PCR was performed using 2x iQ SYBR Green Supermix and a CFX real-time PCR machine (Bio-Rad). PCR conditions were $3 \mathrm{~min}$ at $94{ }^{\circ} \mathrm{C}$ followed by 40 cycles of $94{ }^{\circ} \mathrm{C}, 62-65{ }^{\circ} \mathrm{C}$ for $20 \mathrm{~s}$, and $72{ }^{\circ} \mathrm{C}$ for $1 \mathrm{~min}$ for melting, annealing, and extension steps respectively. The PCR primers were used at a final concentration of $200 \mathrm{nM}$. Cycle thresholds $\left(C_{\mathrm{t}}\right)$ were determined using the CFX software, and relative mRNA levels were determined as described previously after normalization to $18 \mathrm{~S}$ rRNA levels (McConaha et al. 2011). The efficiencies of the PCR were linear between the mRNAs and 18S rRNA and were $>85 \%$. The effects of day of pregnancy and site of sampling on mean relative steady-state mRNA levels between NIS and IS tissues were determined statistically using two-way repeated measures ANOVA. Likewise, the effect of day of pregnancy and mouse genotype on mean relative steady-state mRNA levels in IS tissue from $I / 15^{+/+}$and $/ / 15^{-/-}$mice was determined statistically using two-way repeated measures ANOVA. ANOVA was followed by the use of Duncan multiple range tests to determine differences between the means when warranted. Data collected on a single day of pregnancy were analyzed using $t$-tests to determine the effect of genotype on mRNA levels in IS tissues. All statistical analyses were conducted using SigmaPlot software (Systat Software, Inc., San Jose, CA, USA).

\section{In situ hybridization}

To collect tissue for in situ hybridization, mice were anesthetized, perfused with PBS, and then fixed with paraformaldehyde as described previously (McConaha et al. 2011). Processing of tissue into paraffin was done using routine methods. Five micrometer sections were mounted onto HistoBond glass slides (Statlab, McKinney, TX, USA). Templates for sense and antisense riboprobe synthesis were prepared by PCR and cloned into pGEM-T Easy as described previously (McConaha et al. 2011). PCR primers used are shown in Supplementary Table 3. After sequencing the cDNA clones (UIUC DNA Sequencing Lab), the plasmids were used to generate transcription templates by PCR as described previously (McConaha et al. 2011). After purification of the DNA using a QIAquick PCR purification kit (Qiagen), the template was used to generate digoxigenin (DIG)-labeled riboprobes using MAXIscript T7 and SP6 kits (Applied Biosystems) along with dixoxigenin-11-UTP (Roche). After riboprobe purification using MEGAclear kits (Applied Biosystems), in situ hybridization was performed using antisense DIGlabeled riboprobes exactly as described in detail elsewhere (Simmons et al. 2007). Both antisense and control sense DIGlabeled riboprobes were used for in situ hybridization. Use of sense probes for all target genes studied in the in situ hybridization work of this study did not result in any positive 
hybridization signals (see Supplementary Figure 1, see section on supplementary data given at the end of this article). In some cases, after completion of the in situ staining, the slides were processed for DBA lectin histochemistry exactly as described elsewhere (Eckstrum \& Bany 2011).

\section{Immunohistochemistry and vascular morphometry}

To visualize those cells undergoing proliferation, mice were injected with BrdU $4 \mathrm{~h}$ before tissue collection as previously described (Herington \& Bany 2007b). Uterine sections were de-waxed and hydrated using routine techniques and then exposed to $0.2 \%$ trypsin in PBS at $37^{\circ} \mathrm{C}$ for 10 min for antigen retrieval. After washing the sections in PBS, they were incubated with $1.5 \mathrm{M} \mathrm{HCl}$ for $15 \mathrm{~min}$ and then washed with water. To neutralize the sections, they were covered with borate buffer $(0.1 \mathrm{M}, \mathrm{pH} 8.5)$ for $10 \mathrm{~min}$ and then washed in PBS. Subsequent incubations were carried out using antibody amplifier trays from ProHisto (Columbia, SC, USA) and a horizontal shaker. Sections were next incubated in blocking buffer containing $2 \%$ donkey serum in PBS with $0.05 \%$ tween (PBST) for $60 \mathrm{~min}$. Sections were then incubated with $0.3 \mu \mathrm{g} / \mathrm{ml}$ sheep anti-BrdU (Biodesign International, Saco, ME, USA) and rat anti-mouse CD34 IgG $(0.1 \mu \mathrm{g} / \mathrm{ml})$ (Cedarlane Laboratories, Hornby, ON, Canada) for $1 \mathrm{~h}$. After washing in PBST, the sections were incubated with $0.5 \mu \mathrm{g} / \mathrm{ml}$ biotinylated donkey anti-rat IgG and $1 \mu \mathrm{g} / \mathrm{ml}$ Dye-light 488 donkey antisheep IgG in blocking medium (Jackson ImmunoResearch Laboratories, West Grove, PA, USA) for 60 min. After washing the sections in PBST, they were incubated with $0.5 \mu \mathrm{g} / \mathrm{ml}$ Dye-light 549-conjugated Streptavidin (Jackson ImmunoResearch Laboratories) in PBS for $30 \mathrm{~min}$. After washing with PBST, the slides were incubated with $4^{\prime} 6$-diamidino2-phenylindole (DAPI) in PBS for $10 \mathrm{~min}$ and then washed in PBS. Finally, coverslips were placed over the sections using Fluoromount G mountant (Southern Biotech, Birmingham, $\mathrm{AL}, \mathrm{USA})$.

Slides were examined using a Leica CTR5000 fluorescence microscope equipped with a Retiga 2000JR QImaging Camera and using Qcapture Pro software (Qlmaging, Burnaby, BC, Canada). Endothelial cells were counted as CD34 cells lining the lumens of blood vessels, and BrdU-positive cells were counted as proliferating cells. Photomicrographs were taken with a $20 \times$ objective in CM plus LM and AM regions of the endometrium, and total BrdU-positive and -negative endothelial cells were manually counted in enlarged prints of the photomicrographs from $\mathrm{AM}$ and $\mathrm{LM}$ and $\mathrm{CM}$ uterine regions (from four independent samples). Endothelial cell density was calculated as the number of endothelial cells normalized to area, while proliferation index was calculated as the percent of BrdU-positive endothelial cells or vessels. A minimum of 200 endothelial cells per area were counted in each independent sample. Two-way ANOVA was performed to detect overall differences in the uNK cell subtype densities for each individual day and sub-region using SigmaPlot software (Systat Software, Inc., Chicago, IL, USA). This was followed by the use of Duncan multiple range tests to determine differences between the means.

\section{Supplementary data}

This is linked to the online version of the paper at http://dx.doi. org/10.1530/REP-11-0325.

\section{Declaration of interest}

The authors declare that there is no conflict of interest that could be perceived as prejudicing the impartiality of the research reported.

\section{Funding}

This work was supported by an NIH - Eunice Kennedy Shriver National Institute of Child Health and Human Development (HD049010) grant (to B M Bany). Support from Southern Illinois University was received in the form of Undergraduate Research Assistantships (to K S Eckstrum and C A Scott) and an Undergraduate REACH Award (to K S Eckstrum).

\section{Acknowledgements}

The authors thank Jen Herington and Melinda McConaha for technical assistance with some of the real-time PCR assays and cDNA clone preparation respectively.

\section{References}

Abrahamsohn PA \& Zorn TM 1993 Implantation and decidualization in rodents. Journal of Experimental Zoology 266 603-628. (doi:10.1002/ jez.1402660610)

Allen MP \& Nilsen-Hamilton M 1998 Granzymes D, E, F, and G are regulated through pregnancy and by IL-2 and IL-15 in granulated metrial gland cells. Journal of Immunology $1612772-2779$.

Ashkar AA, Black GP, Wei Q, He H, Liang L, Head JR \& Croy BA 2003 Assessment of requirements for IL-15 and IFN regulatory factors in uterine NK cell differentiation and function during pregnancy. Journal of Immunology 171 2937-2944.

Bany BM \& Cross JC 2006 Post-implantation mouse conceptuses produce paracrine signals that regulate the uterine endometrium undergoing decidualization. Developmental Biology 294 445-456. (doi:10.1016/j. ydbio.2006.03.006)

Barber EM \& Pollard JW 2003 The uterine NK cell population requires IL-15 but these cells are not required for pregnancy nor the resolution of a Listeria monocytogenes infection. Journal of Immunology 171 37-46.

Bolstad BM, Irizarry RA, Astrand M \& Speed TP 2003 A comparison of normalization methods for high density oligonucleotide array data based on variance and bias. Bioinformatics 19 185-193.

Calderwood SK, Mambula SS \& Gray PJ Jr 2007a Extracellular heat shock proteins in cell signaling and immunity. Annals of the New York Academy of Sciences 1113 28-39. (doi:10.1196/annals.1391.019)

Calderwood SK, Mambula SS, Gray PJ Jr \& Theriault JR 2007 b Extracellular heat shock proteins in cell signaling. FEBS Letters 581 3689-3694. (doi:10.1016/j.febslet.2007.04.044)

Chakraborty I, Das SK \& Dey SK 1995 Differential expression of vascular endothelial growth factor and its receptor mRNAs in the mouse uterus around the time of implantation. Journal of Endocrinology 147 339-352. (doi:10.1677/joe.0.1470339)

Cho JH, Yoon MS, Koo JB, Kim YS, Lee KS, Lee JH \& Han JS 2011 The progesterone receptor as a transcription factor regulates phospholipase D1 expression through independent activation of protein kinase $A$ and Ras during 8-Br-cAMP-induced decidualization in human endometrial stromal cells. Biochemical Journal 436 181-191. (doi:10.1042/BJ20101614) 
Conus S \& Simon HU 2010 Cathepsins and their involvement in immune responses. Swiss Medical Weekly 140 w13042. (doi:10.4414/smw.2010. 13042)

Croy BA, Esadeg S, Chantakru S, van den Heuvel M, Paffaro VA, He $\mathbf{H}$, Black GP, Ashkar AA, Kiso Y \& Zhang J 2003a Update on pathways regulating the activation of uterine natural killer cells, their interactions with decidual spiral arteries and homing of their precursors to the uterus. Journal of Reproductive Immunology 59 175-191. (doi:10.1016/S01650378(03)00046-9)

Croy BA, He H, Esadeg S, Wei Q, McCartney D, Zhang J, Borzychowski A, Ashkar AA, Black GP, Evans SS et al. 2003 $b$ Uterine natural killer cells: insights into their cellular and molecular biology from mouse modelling. Reproduction 126 149-160. (doi:10.1530/rep.0.1260149)

Croy BA, Zhang J, Tayade C, Colucci F, Yadi H \& Yamada AT 2010 Analysis of uterine natural killer cells in mice. Methods in Molecular Biology 612 465-503. (doi:10.1007/978-1-60761-362-6_31)

Demir R, Yaba A \& Huppertz B 2010 Vasculogenesis and angiogenesis in the endometrium during menstrual cycle and implantation. Acta Histochemica 112 203-214. (doi:10.1016/j.acthis.2009.04.004)

Dong JT \& Chen C 2009 Essential role of KLF5 transcription factor in cell proliferation and differentiation and its implications for human diseases. Cellular and Molecular Life Sciences 66 2691-2706. (doi:10.1007/ s00018-009-0045-z)

Douglas NC, Tang H, Gomez R, Pytowski B, Hicklin DJ, Sauer CM, Kitajewski J, Sauer MV \& Zimmermann RC 2009 Vascular endothelial growth factor receptor 2 (VEGFR-2) functions to promote uterine decidual angiogenesis during early pregnancy in the mouse. Endocrinology 150 3845-3854. (doi:10.1210/en.2008-1207)

Dunn CL, Kelly RW \& Critchley HO 2003 Decidualization of the human endometrial stromal cell: an enigmatic transformation. Reproductive Biomedicine Online 7 151-161. (doi:10.1016/S1472-6483(10)61745-2)

Eckstrum K \& Bany BM 2011 Tumor necrosis factor receptor subfamily 9 (Tnfrsf9) gene is expressed in distinct cell populations in mouse uterus and conceptus during implantation period of pregnancy. Cell and Tissue Research 344 567-576. (doi:10.1007/s00441-011-1171-0)

Enomoto A, Omae F, Miyazaki M, Kozutsumi Y, Yubisui T \& Suzuki A 2006 Dihydroceramide:sphinganine $\mathrm{C}$-4-hydroxylation requires Des2 hydroxylase and the membrane form of cytochrome b5. Biochemical Journal 397 289-295. (doi:10.1042/BJ20051938)

Gellersen B, Brosens IA \& Brosens JJ 2007 Decidualization of the human endometrium: mechanisms, functions, and clinical perspectives. Seminars in Reproductive Medicine 25 445-453. (doi:10.1055/s-2007-991042)

Goebeler V, Poeter M, Zeuschner D, Gerke V \& Rescher U 2008 Annexin A8 regulates late endosome organization and function. Molecular Biology of the Cell 19 5267-5278. (doi:10.1091/mbc.E08-04-0383)

Halder JB, Zhao X, Soker S, Paria BC, Klagsbrun M, Das SK \& Dey SK 2000 Differential expression of VEGF isoforms and VEGF(164)-specific receptor neuropilin-1 in the mouse uterus suggests a role for $\operatorname{VEGF(164)~in~vascular~permeability~and~angiogenesis~during~implan-~}$ tation. Genesis 26 213-224. (doi:10.1002/(SICI)1526-968X(200003) 26:3<213::AID-GENE7> 3.0.CO;2-M)

Hao Z, Li X, Qiao T, Zhang J, Shao X \& Fan D 2006 Distribution of CIAPIN1 in normal fetal and adult human tissues. Journal of Histochemistry and Cytochemistry 54 417-426. (doi:10.1369/jhc.5A6753.2005)

He Y, Smith SK, day KA, Clark DE, Licence DR \& Charnock-Jones DS 1999 Alternative splicing of vascular endothelial growth factor (VEGF)-R1 (FLT-1) pre-mRNA is important for the regulation of VEGF activity. Molecular Endocrinology 13 537-545. (doi:10.1210/me.13.4.537)

Herington JL \& Bany BM 2007a The conceptus increases secreted phosphoprotein 1 gene expression in the mouse uterus during the progression of decidualization mainly due to its effects on uterine natural killer cells. Reproduction 133 1213-1221. (doi:10.1530/REP-07-0085)

Herington JL \& Bany BM $2007 b$ Effect of the conceptus on uterine natural killer cell numbers and function in the mouse uterus during decidualization. Biology of Reproduction 76 579-588. (doi:10.1095/biolreprod. 106.056630)

Herington JL, Underwood T, McConaha M \& Bany BM 2009 Paracrine signals from the mouse conceptus are not required for the normal progression of decidualization. Endocrinology 150 4404-4413. (doi:10. 1210/en.2009-0036)

Hess AP, Hirchenhain J, Schanz A, Talbi S, Hamilton AE, Giudice LC \& Krussel JS 2006 Angiopoietin-1 and -2 mRNA and protein expression in mouse preimplantation embryos and uteri suggests a role in angiogenesis during implantation. Reproduction, Fertility, and Development 18 509-516. (doi:10.1071/RD05110)

Hong SH, Nah HY, Lee JY, Lee YJ, Lee JW, Gye MC, Kim CH, Kang BM \& Kim MK 2004 Estrogen regulates the expression of the small proline-rich 2 gene family in the mouse uterus. Molecules and Cells 17 477-484.

Ika SA, Qi XF \& Chen ZX 2009 Regulatory function and expression of rap1gap gene in hematopoietic cells-review. Zhongguo Shi Yan Xue Ye Xue Za Zhi 17 1093-1096.

Joswig A, Gabriel HD, Kibschull M \& Winterhager E 2003 Apoptosis in uterine epithelium and decidua in response to implantation: evidence for two different pathways. Reproductive Biology and Endocrinology 144. (doi:10.1186/1477-7827-1-44)

Jungers KA, Le Goff C, Somerville RP \& Apte SS 2005 Adamts9 is widely expressed during mouse embryo development. Gene Expression Patterns 5 609-617. (doi:10.1016/j.modgep.2005.03.004)

Kalkunte SS, Mselle TF, Norris WE, Wira CR, Sentman CL \& Sharma S 2009 Vascular endothelial growth factor $C$ facilitates immune tolerance and endovascular activity of human uterine NK cells at the maternal-fetal interface. Journal of Immunology 182 4085-4092. (doi:10.4049/ jimmunol.0803769)

Kallio MA, Tuimala JT, Hupponen T, Klemela P, Gentile M, Scheinin I, Koski M, Kaki J \& Korpelainen El 2011 Chipster: user-friendly analysis software for microarray and other high-throughput data. BMC Genomics 12507.

Kaneko-Tarui T, Zhang L, Austin KJ, Henkes LE, Johnson J, Hansen TR \& Pru JK 2007 Maternal and embryonic control of uterine sphingolipidmetabolizing enzymes during murine embryo implantation. Biology of Reproduction 77 658-665. (doi:10.1095/biolreprod.107.061044)

Kang BY, Miaw SC \& Ho IC 2005 ROG negatively regulates T-cell activation but is dispensable for Th-cell differentiation. Molecular and Cellular Biology 25 554-562. (doi:10.1128/MCB.25.2.554-562.2005)

King A, Allan DS, Bowen M, Powis SJ, Joseph S, Verma S, Hiby SE, McMichael AJ, Loke YW \& Braud VM 2000 HLA-E is expressed on trophoblast and interacts with CD94/NKG2 receptors on decidual NK cells. European Journal of Immunology 30 1623-1631. (doi:10.1002/ 1521-4141(200006)30:6 < 1623::AID-IMMU1623>3.0.CO;2-M)

Koo BH, Coe DM, Dixon LJ, Somerville RP, Nelson CM, Wang LW, Young ME, Lindner DJ \& Apte SS 2010 ADAMTS9 is a cell-autonomously acting, anti-angiogenic metalloprotease expressed by microvascular endothelial cells. American Journal of Pathology 176 1494-1504. (doi:10.2353/ajpath.2010.090655)

Lash GE, SchiessI B, Kirkley M, Innes BA, Cooper A, Searle RF, Robson SC \& Bulmer JN 2006 Expression of angiogenic growth factors by uterine natural killer cells during early pregnancy. Journal of Leukocyte Biology 80 572-580. (doi:10.1189/jlb.0406250)

Lash GE, Robson SC \& Bulmer JN 2010 Review: functional role of uterine natural killer (uNK) cells in human early pregnancy decidua. Placenta 31 (Suppl) S87-S92. (doi:10.1016/j.placenta.2009.12.022)

Laws MJ, Taylor RN, Sidell N, DeMayo FJ, Lydon JP, Gutstein DE, Bagchi MK \& Bagchi IC 2008 Gap junction communication between uterine stromal cells plays a critical role in pregnancy-associated neovascularization and embryo survival. Development 135 2659-2668. (doi:10.1242/dev. 019810)

Lee KY, Jeong JW, Wang J, Ma L, Martin JF, Tsai SY, Lydon JP \& DeMayo FJ $2007 \mathrm{Bmp} 2$ is critical for the murine uterine decidual response. Molecular and Cellular Biology 27 5468-5478. (doi:10.1128/MCB.00342-07)

Li G, Huang W, Xia Q, Yang K, Liu R, Zhu H \& Jiang W 2008 Role of uterine natural killer cells in angiogenesis of human decidua of the first-trimester pregnancy. Science in China. Series C, Life Sciences/Chinese Academy of Sciences 51 111-119. (doi:10.1007/s11427-008-0027-7)

Li Y, Hofmann M, Wang Q, Teng L, Chlewicki LK, Pircher H \& Mariuzza RA 2009 Structure of natural killer cell receptor KLRG1 bound to E-cadherin reveals basis for $\mathrm{MHC}$-independent missing self recognition. Immunity 31 35-46. (doi:10.1016/j.immuni.2009.04.019)

Lim H, Paria BC, Das SK, Dinchuk JE, Langenbach R, Trzaskos JM \& Dey SK 1997 Multiple female reproductive failures in cyclooxygenase 2-deficient mice. Cell 91 197-208. (doi:10.1016/S0092-8674(00)80402-X)

Ma H \& Zhu G 2007 Expression of angiopoietin-1/-2 in the process of mouse embryo implantation. Journal of Huazhong University of Science and Technology. Medical Sciences 27 200-202. (doi:10.1007/s11596007-0225-8) 
Ma GT, Roth ME, Groskopf JC, Tsai FY, Orkin SH, Grosveld F, Engel JD \& Linzer DI 1997 GATA-2 and GATA-3 regulate trophoblast-specific gene expression in vivo. Development 124 907-914.

Matsumoto H, Ma WG, Daikoku T, Zhao X, Paria BC, Das SK, Trzaskos JM \& Dey SK 2002 Cyclooxygenase-2 differentially directs uterine angiogenesis during implantation in mice. Journal of Biological Chemistry 277 29260-29267. (doi:10.1074/jbc.M203996200)

McConaha ME, Eckstrum K, An J, Steinle JJ \& Bany BM 2011 Microarray assessment of the influence of the conceptus on gene expression in the mouse uterus during decidualization. Reproduction 141 511-527. (doi:10.1530/REP-10-0358)

McGrath E, Ryan EJ, Lynch L, Golden-Mason L, Mooney E, Eogan M, O'Herlihy C \& O'Farrelly C 2009 Changes in endometrial natural killer cell expression of CD94, CD158a and CD158b are associated with infertility. American Journal of Reproductive Immunology 61 265-276. (doi:10.1111/j.1600-0897.2009.00688.x)

Monk JM, Leonard S, McBey BA \& Croy BA 2005 Induction of murine spiral artery modification by recombinant human interferon-gamma. Placenta 26 835-838. (doi:10.1016/j.placenta.2004.10.016)

Morison NB, Zhang J, Kaitu'u-Lino TJ, Fraser IS \& Salamonsen LA 2007 The long-term actions of etonogestrel and levonorgestrel on decidualized and non-decidualized endometrium in a mouse model mimic some effects of progestogen-only contraceptives in women. Reproduction 133 309-321. (doi:10.1530/rep.1.01171)

Nagai R, Suzuki T, Aizawa K, Shindo T \& Manabe I 2005 Significance of the transcription factor KLF5 in cardiovascular remodeling. Journal of Thrombosis and Haemostasis 3 1569-1576. (doi:10.1111/j.1538-7836. 2005.01366.x)

Pampfer S \& Donnay I 1999 Apoptosis at the time of embryo implantation in mouse and rat. Cell Death and Differentiation 6 533-545. (doi:10.1038/ sj.cdd.4400516)

Parr EL, Young LH, Parr MB \& Young JD 1990 Granulated metrial gland cells of pregnant mouse uterus are natural killer-like cells that contain perforin and serine esterases. Journal of Immunology 145 2365-2372.

Petitbarat M, Serazin V, Dubanchet S, Wayner R, de Mazancourt P, Chaouat G \& Ledee N 2010 Tumor necrosis factor-like weak inducer of apoptosis (TWEAK)/fibroblast growth factor inducible-14 might regulate the effects of interleukin 18 and 15 in the human endometrium. Fertility and Sterility 94 1141-1143. (doi:10.1016/j.fertnstert.2009.10.049)

Ramathal CY, Bagchi IC, Taylor RN \& Bagchi MK 2010 Endometrial decidualization: of mice and men. Seminars in Reproductive Medicine 28 17-26. (doi:10.1055/s-0029-1242989)

Ruvolo PP 2003 Intracellular signal transduction pathways activated by ceramide and its metabolites. Pharmacological Research 47 383-392. (doi:10.1016/S1043-6618(03)00050-1)

Santoni A, Carlino C \& Gismondi A 2008 Uterine NK cell development, migration and function. Reproductive Biomedicine Online 16 202-210. (doi:10.1016/S1472-6483(10)60575-5)

Shibata M, Ishii J, Koizumi H, Shibata N, Dohmae N, Takio K, Adachi H, Tsujimoto M \& Arai H 2004 Type F scavenger receptor SREC-I interacts with advillin, a member of the gelsolin/villin family, and induces neuritelike outgrowth. Journal of Biological Chemistry 279 40084-40090. (doi:10.1074/jbc.M403844200)

Silacci P, Mazzolai L, Gauci C, Stergiopulos N, Yin HL \& Hayoz D 2004 Gelsolin superfamily proteins: key regulators of cellular functions. Cellular and Molecular Life Sciences 61 2614-2623. (doi:10.1007/ s00018-004-4225-6)

Simmons DG, Fortier AL \& Cross JC 2007 Diverse subtypes and developmental origins of trophoblast giant cells in the mouse placenta. Developmental Biology 304 567-578.
Smyth GK 2004 Linear models and empirical bayes methods for assessing differential expression in microarray experiments. Statistical Applications in Genetics and Molecular Biology 3 Article3.

Soderstrom K, Corliss B, Lanier LL \& Phillips JH 1997 CD94/NKG2 is the predominant inhibitory receptor involved in recognition of HLA-G by decidual and peripheral blood NK cells. Journal of Immunology 159 1072-1075.

Stoeckle C, Gouttefangeas C, Hammer M, Weber E, Melms A \& Tolosa E 2009 Cathepsin W expressed exclusively in CD8 + T cells and NK cells, is secreted during target cell killing but is not essential for cytotoxicity in human CTLs. Experimental Hematology 37 266-275. (doi:10.1016/j. exphem.2008.10.011)

Sur I 2009 Kruppel-like factors 4 and 5: unity in diversity. Current Genomics 10 594-603. (doi:10.2174/138920209789503932)

Torry DS, Leavenworth J, Chang M, Maheshwari V, Groesch K, Ball ER \& Torry RJ 2007 Angiogenesis in implantation. Journal of Assisted Reproduction and Genetics 24 303-315. (doi:10.1007/s10815-0079152-7)

Tsygankova OM, Ma C, Tang W, Korch C, Feldman MD, Lv Y, Brose MS \& Meinkoth JL 2010 Downregulation of Rap1GAP in human tumor cells alters cell/matrix and cell/cell adhesion. Molecular and Cellular Biology 30 3262-3274. (doi:10.1128/MCB.01345-09)

Verma S, King A \& Loke YW 1997 Expression of killer cell inhibitory receptors on human uterine natural killer cells. European Journal of Immunology 27 979-983. (doi:10.1002/eji.1830270426)

Wang C, Umesaki N, Nakamura H, Tanaka T, Nakatani K, Sakaguchi I, Ogita S \& Kaneda K 2000 Expression of vascular endothelial growth factor by granulated metrial gland cells in pregnant murine uteri. Cell and Tissue Research 300 285-293. (doi:10.1007/s004410000198)

Wang C, Tanaka T, Nakamura H, Umesaki N, Hirai K, Ishiko O, Ogita S \& Kaneda K 2003 Granulated metrial gland cells in the murine uterus: localization, kinetics, and the functional role in angiogenesis during pregnancy. Microscopy Research and Technique 60 420-429. (doi:10. 1002/jemt.10280)

Watanabe N, Kurabayashi M, Shimomura Y, Kawai-Kowase K, Hoshino Y, Manabe I, Watanabe M, Aikawa M, Kuro-o M, Suzuki T et al. 1999 BTEB2, a Kruppel-like transcription factor, regulates expression of the SMemb/Nonmuscle myosin heavy chain B (SMemb/NMHC-B) gene. Circulation Research 85 182-191.

Wex T, Buhling F, Wex H, Gunther D, Malfertheiner P, Weber E \& Bromme D 2001 Human cathepsin W, a cysteine protease predominantly expressed in NK cells, is mainly localized in the endoplasmic reticulum. Journal of Immunology 167 2172-2178.

Wong AL, Haroon ZA, Werner S, Dewhirst MW, Greenberg CS \& Peters KG 1997 Tie2 expression and phosphorylation in angiogenic and quiescent adult tissues. Circulation Research 81 567-574.

Zhang JH, Yamada AT \& Croy BA 2009 DBA-lectin reactivity defines natural killer cells that have homed to mouse decidua. Placenta 30 968-973. (doi:10.1016/j.placenta.2009.08.011)

Zhang J, Chen Z, Smith GN \& Croy BA 2011 Natural killer cell-triggered vascular transformation: maternal care before birth? Cellular \& Molecular Immunology 8 1-11. (doi:10.1038/cmi.2010.38)

Received 31 August 2011

First decision 26 October 2011

Revised manuscript received 23 November 2011

Accepted 20 December 2011 